\title{
EL CONCEPTO REALIMENTACIÓN Y SU SIGNIFICADO EN EL ÁMBITO PEDAGÓGICO
}

\section{THE CONCEPT FEEDBACK AND ITS MEANING IN THE EDUCATIONAL THEORY}

\section{FELIPE VEGA MANCERA}

Universidad de Málaga. Departamento de Teoria e Historia de la Educación. Facultad de Ciencias de la Educación. Campus de Teatinos. 29071 Málaga.

Amb estima al Dr. Sanvisens, en el record.

\section{RESUMEN}

Este artículo comprende un estudio minucioso sobre el concepto de realimentación. Se describe su desarrollo histórico, su presencia en diversas disciplinas científicas -en particular en las CC. Sociales-, analizando su influencia en el orden de las ideas y los métodos, lo que le ha llevado a convertirse en una de las principales metáforas científicas de la actualidad. Su incorporación al lenguaje pedagógico, por vía de las corrientes sistémicas y cibernéticas, merece un estudio crítico, en el que se describan los niveles a los que opera, su relación con otros conceptos y procesos, y su posición central en las modernas teorías de la educación; con especial hincapié en las aportaciones del Dr. Sanvisens.

\section{SUMMARY}

The purpose of this paper is to analyze the concept feedback. From Watt "Governor" (1790) and the initial theoretical work developed by J. Maxwell (1868), including the cybernetics concepts developed in the fifties, in this paper we revise the conceptual influences and the methodological and thecnological applications in different disciplines, with special attention to the Social Sciences field. The feedback concept is related with other concepts such as: The Systems Dynamic's, the Biofeedback thecnics, the sociological systemic models, the family therapy... Thorough discussion is deserved to the application of this concept in the 
Educational Theory field. Specifically we analyze the contributions made by the humanistic cybernetic proposed by A. Sanvisens.

Aquí se pretende analizar un concepto de uso frecuente en la terminología pedagógica contemporánea y que procede de otras disciplinas. Precisamente su origen foráneo y el uso generalizado que de él se hace en otros muchos campos de la ciencia, aconsejan un estudio detallado de su significación, aplicación y recorrido histórico; máxime, si consideramos su importancia en la red conceptual de las Ciencias de la Educación, en particular en su concepción tecnológica o de orientación sistémico-cibernética.

Es necesario adelantar que dicho análisis ha sido ya resuelto brillantemente por otros autores - a los que nos referiremos a lo largo del texto- pero, generalmente, desde perspectivas muy distintas, especializadas $\mathrm{y}$, consecuentemente, reflejadas en una bibliografía dispersa. Lo que en sí mismo no resultaría un problema, toda vez que el Profesor Alejandro Sanvisens, hace ya más de treinta años, resolvió perfectamente en distintos trabajos su significación, la aplicación más idónea a la Pedagogía y, aún más, desarrolló originalmente toda una línea de pensamiento que excede por su trascendencia a una buena parte de las fuentes que utilizó. De este trabajo, no siempre reconocido en su justo valor ${ }^{1}$, somos deudores. Desgraciadamente, una parte de estos trabajos resultan hoy difíciles de localizar o nos remiten - por su título- a cuestiones que parecen ya superadas.

En consecuencia, el único fin de este texto es sintetizar una información relativamente dispersa, actualizar algunos aspectos -fundamentalmente aplicadosy analizar pormenorizadamente el uso del término en el ámbito pedagógico, en la medida de nuestras posibilidades. Para ello comenzaremos con una descripción de los primeros mecanismos autorregulados, comentaremos los primeros trabajos sobre cibernética (con atención a algunos precedentes teóricos), su aplicación a los distintos campos científicos - tanto en el plano conceptual como metodológico y aplicado-; para centrarnos, por último, en su significación pedagógica.

Antes de empezar resultaría conveniente aclarar al lector por qué comenzamos precisamente con una aplicación técnica y no por su correspondiente formulación teórica, aspecto en absoluto anecdótico. Aún hoy resulta frecuente la presentación del progreso científico en la clásica secuencia "Investigación Básica-Investigación Aplicada-Tecnología", de marcado carácter deductivo. En este sentido, se pretende

1. Un estudio pormenorizado de la cronología de sus trabajos sobre Teoría de Grupos, automatismo, Cibernética, etc., que demuestra su carácter predecesor en este país, y aún en otros ámbitos europeos, se encuentra en la erudita presentación de COLOM, A. J. al trabajo de recopilación de 1984: SANVISENS, A.: Cibernética de lo Humano. Oikos-tau, Barcelona. Sólo como muestra y ciñéndonos al ámbito educativo, baste recordar que las referencias al aprendizaje, el desarrollo personal o los aspectos sociales de la educación contenidos en sus trabajos del período 1956-1970 son contemporáneos a las publicaciones de Landa (1962), von Cube (1965), Müller (1967), Englert (1967) o Zypkin (1970); y en un sentido más amplio, en referencia al desarrollo de los conceptos sistémicos, contemporáneos a los primeros trabajos de este enfoque en Sociología (Díez Nicolás), Economía (Sampedro, Tamames,...) y Geografía Urbana, publidados en nuestro país. 
que las aplicaciones industriales, por ejemplo, resultan necesariamente fruto de la resolución previa de aspectos teóricos, formales o básicos en el laboratorio; aún cuando se acepte que los problemas surgidos en la implantación y uso de estas innovaciones generen, a su vez, otras hipótesis de laboratorio. En realidad, hace ya mucho tiempo que la historia de la ciencia y, más recientemente, la etnografía de laboratorio demostraron la relativa falsedad del modelo. La traslación al lenguaje científico y la posterior formulación de leyes o conceptos procedentes de soluciones y técnicas ya desarrolladas en la cultura vulgar es un caso relativamente común. Pero ha sido en la segunda mitad de este siglo cuando el verdadero desarrollo de la tecnología moderna, así como el advenimiento de métodos de investigación más dinámicos, han puesto de manifiesto el verdadero carácter simbiótico de la relación tecnología-pensamiento científico, presente a lo largo de la historia. De hecho, hasta el surgimiento de la energía nuclear y la ingeniería genética (Aracil, 1986) lo común fue que las aplicaciones técnicas precedieran siempre al conocimiento científico. La actual comprensión de la "tecnología" como un método de resolución eficaz de problemas prácticos ajustado a las leyes y conocimientos científicos y estrecha relación de interdependenca con éstos, parece resolver la disputa.

En todo caso, de lo que no existe la menor duda es que la invención de mecanismos autorregulados es muy anterior a la formulaicón científica de la realimentación y que, además, ésta última (y aún el surgimiento de la Cibernética toda, como luego veremos) se debe a la presencia de éstos. De hecho, aunque suele tomarse el regulador de bolas de Watt (1970) como el primer mecanismo autorregulado "stricto sensu", ya existían siglos atrás otros aparatos que pueden calificarse como tales: así el mecanismo del reloj de agua (clepsidra), un reloj de luz (descrito en 1206 por Al-Jazarí) o las veletas y pequeñas palas auxiliares que permitían en ciertos molinos mantenerlos permanentemente orientados al viento siguiendo sus cambios de dirección (Sanvisens, 1959). En estos simples mecanismos se encuentra ya la capacidad de autorregulación: es decir, añadidos o instalados en una máquina son capaces de ajustarla automáticamente (de forma autónoma) a un objetivo o función prescrita. Tenemos así la posibilidad de que la máquina se ajuste por sí misma a ciertos cambios externos o de las condiciones de su trabajo. Esta es la base del automatismo que, por cierto, nada tiene que ver en términos rigurosos con los muñecos "autómatas", tan populares en el siglo XVIII, aunque se utilice la misma palabra, en algunos textos, para designar a ciertos equipos o simuladores servomecánicos.

Pero volviendo al regulador de James Watt (1736-1819)2 desentrañemos su importancia. Nos encontramos con una invención que supone un verdadero salto cualitativo. La transformación termodinámica que realiza la máquina de vapor (calor a fuerza mecánica) y su aplicación a múltiples labores - es innecesario citar aquí su trascendencia en la génesis de la Revolución Industrial- plantea algunos problemas en relacción con la eficiencia. Bien sea, como indica Sanvisens, por la monotonía del trabajo del operario al regular manualmente el movimiento del émbolo de la máqui-

2. Este Ingeniero escocés también había mejorado la máquina de vapor de Newcomen y transformado el movimiento del pistón en rotatorio, aunque tales modificaciones no se aplicarían a gran escala hasta el período 1820-40 (Matillas, 1993). 
na fija de vapor, bien, como lo hacen más acertadamente otros autores, por impedir que la máquina se embalara al disminuir la carga, resultaba necesario mantener a velocidad constante el giro del volante. La velocidad debería permanecer ajustada al régimen requerido con independencia del calor producido en la combustión o que la máquina trabajara "en vacío". El invento de Watt permitió resolverlo por la adopción de un mecanismo que, una vez ajustado, sería capaz de comparar la velocidad real de la máquina con la velocidad ideal, definida previamente, gobernando ella misma la cantidad de vapor insuflada a la caldera; se establece así un ciclo indefinido - al que nos referiremos a partir de ahora como "bucle" de realimentación- de comparación (medida de la discrepancia: v. real-v. de referencia) y órdenes de control a la válvula del vapor, regidas precisamente por la acción del regulador.

Otros artilugios semejantes por su función y que suelen citarse en las revisiones históricas son el "repetidor" con realimentación negativa y los "servomecanismos", ambos desarrollados ya en nuestra centuria. Se trata, en el primer caso, de un componente de las redes eléctricas que permite controlar la señal, reduciendo al máximo los problemas de estabilidad generados por los amplificadores. Este mecanismo, inventado por los laboratorios Bell en la década de los 20 y que supuso el comienzo de la Electrónica, presenta la característica común a todos los "autorreguladores" de utilizar una parte de la energía de salida para emplearla en el control del propio aparato. En su caso además, se califica de realimentación negativa porque su funcionamiento trae como consecuencia una reducción de la energía de entrada.

Los servomecanismos, por su parte, permitieron dominar eficazmente las enormes palas del timón de los navíos modernos. Básicamente se trata de introducir, en el sistema mecánico tradicional que conectaba la rueda del timón a la pala de éste, un motor capaz de modificar el ángulo de forma rápida y exacta, sustituyendo la fuerza del timonel. El proceso se inicia cuando un movimiento de la rueda produce una diferencia (un ángulo de error) entre la nueva posición marcada y la posición real del eje de la pala. Un servoamplificador calcula esta diferencia y actúa sobre un servomotor que se pone en funcionamiento empujando la pala hasta que el ángulo de error o discrepancia es cero. Obsérvese que el ciclo de relaciones causales es esencialmente similar al antes descrito para el regulador de bolas, pero que tanto el repetidor como los servomecanismos se rigen por una referencia variable (señal telefónica o posición de la rueda).

Esta peculiaridad de que el objetivo o señal de referencia sea variable y, más ampliamente, presente un comportamiento oscilante o estocástico (probabilístico) se puso claramente de manifiesto en el problema al que se enfrentaron Norbert Wiener y Julian Bigelow en la década de los 40 y que generaría finalmente el surgimiento de la Cibernética como disciplina autónoma. Por encargo del Ejército Norteamericano, incorporado ya a la II Guerra Mundial, Wiener - eminente matemático, profesor del Instituto de Tecnología de Massachussetts, colaborador habitual en investigación sobre electrónica y conocedor de los avances en biologíaestudia la mejora de los cañones antiaéreos. La resolución técnica del problema se plasmaría en un sistema que automatizara el cálculo de la trayectoria del objetivo y los proyectiles, a partir de la información registrada en el radar, y el movimiento y 
disparo del cañón. Para ello fue necesario el desarrollo de una teoría matemática (sobre ecuaciones integrales y análisis de Fourier) capaz de integrar los fenómenos estocásticos $^{3}$ : como el reflejo miotático, el temblor intencional y, en general, todos los procesos neuromusculares involucrados en el equilibrio y el movimiento y, paradigmáticamente, la psicomotricidad de los movimientos voluntarios, de los que más tarde trataremos. Precisamente los conocimientos de biología de Wiener y su relación con A. Rosenblueth - del Harvard Medical School- permitirían en el 42 la formulación de una teoría del control y la realimentación en las máquinas y los animales (véase el título de la obra de Wiener del 48).

En suma, en este momento histórico se produce la necesaria - y por otro lado genial - confluencia entre desarrollos técnicos y teóricos, las similitudes entre distintos modelos de explicación en diferentes ciencias y los sucesos y personas necesarios para servir de catalizador y generar una nueva disciplina, con un claro componente transversal o de nexo entre las ya existentes. No cabe duda que la invención y uso de los mecanismos autorregulados y el desarrollo de explicaciones y teorías sobre la autorregulación son centrales en esta historia.

Como acabamos de afirmar unas líneas más arriba, fueron Wiener y sus colaboradores los encargados de desarrollar una teoría completa sobre la comunicación y el control, pero es necesario matizar que otros estudiosos avanzaron algunas ideas importantes con antelación. Con independencia de algunos conceptos filosóficos y científicos que fracturaron la hegemonía de las explicaciones deterministas (basadas en relaciones causales lineales) son interesantes de mencionar:

- Los trabajos teórico-técnicos del inglés James Clerk Maxwell (1831-1879), creador de la teoría del electromagnetismo, que en 1868 publicó una explicación teórica del regulador de Watt, al tiempo que propuso interesantes consecuencias sobre la aplicación de estos mecanismos. De hecho, este trabajo suele considerarse la primera publicación relativa a la cibernética.

- Los desarrollos del concepto realimentación, que al comienzo de la década de los 30, realizaron H.S. Black y H. Nyquist.

- El principio de Le Chatelier, derivado de la termodinámica, que afirmaba que "toda alteración del estado de equilibrio de un sistema provoca cambios de parte de este, que tienden a restablecer el equilibrio primitivo" (Neuschlosz, 1939, 180), como se ponía de manifiesto en el efecto del calor sobre el equilibrio de las reacciones químicas reversibles, el efecto calórico de Peltier, la inducción y el electromagnetismo, etc...

- Las ideas derivadas de la Termodinámica y, en especial, las distinciones entre sistemas abiertos y cerrados, la entropía y los comportamientos que la contrarrestan (anentropía, entropía negativa...) estrechamente vinculados a la idea de realimentación (vid. Aznar, 1978).

- Los trabajos en el campo de la Fisiología, en especial los de Walter Cannon sobre homeostasis, a los que más tarde nos referiremos con detalle.

3. Todo el episodio de trabajo interdisciplinar que se realizó antes y durante el desarrollo del sistema de tiro antiaéreo se describe pormenorizadamente en la Introducción de Wiener (1995). 
- Las investigaciones de Walter Shanon, coetáneas a las de Wiener, y que permiten formalizar matemáticamente los procesos de transmisión de la información, imprescindibles para la generalización de las teorías sobre la autorregulación a problemas no estrictamente físicos.

- Y, naturalmente, las mencionadas innovaciones tecnológicas y sus importantísimas repercusiones en el sistema de producción, de comunicación y la vida social en general ${ }^{4}$.

En todos los precedentes listados, el concepto de realimentación está explícita o implícitamente considerado. Este término que procede del ingés "feed-back" (literalmente: alimentación hacia atrás) y que suele traducirse por el citado de "realimentación" o alimentación de retorno - y también con frecuencia por "retroalimentación" 5 - así como retrocompensación, reinformación, retroacción, autogestión del control y autorregulación, puede definirse como «una propiedad de un sistema de lazo cerrado que permite que la salida (o cualquier otra variable controlada del sistema) sea comparada con la entrada al sistema (o con una entrada a cualquier componente interno del sistema o con un subsistema de éste) de tal manera que se pueda establecer la acción de control apropiada como función de la entrada y la salida" (Distefano, Stubbern y Willians, 1981, 4) aunque «...En principio, puede parecer simplemente un aspecto físico y mecánico que expresa la retroacción de un sistema dinámico a fin de compensar, de mantener o de aumentar el resultado de su acción. La retroacción, con la detectación del efecto y la consiguiente comparación con el objetivo (pattern, modelo, nivel, valor, ideal...) del sistema, promueve una información complementaria (reacción) a fin de regular debidamente dicho efecto, la propia operatividad del sistema en búsqueda de su objetivo prefijado" (Sanvisens, 1983 b). Importante esta matización, pues pone de manifiesto una de las aportaciones esenciales de la Cibernética al pensamiento científico, esto es: la materia y energía no bas-

4. Posiblemente la lista debería completarse con una mención a la Teoría General de Sistemas de Von Bertalanffy. Las similitudes en ciertos aspectos teóricos y epistemológicos (carácter interdisciplinar, cross-fertilization, comprensión holística de la realidad, notaciones comunes, etc...) presuponen un desarrollo paralelo de ambas líneas de pensamiento. De hecho, no es infrecuente encontrar clasificaciones que tienden a incluir una de las dos disciplinas como un subconjunto extensión de la otra (bien es verdad, que con más frecuencia los sistemistas defienden la tesis de concebir la Cibernética como el estudio de un tipo especial de sistemas: Vid. Von Bertalanffy, 1981, I, -si bien se reconoce abiertamente el nacimiento independiente de ésta-). De otro lado, la cronología de los escritos de Von Bertalanffy y Wiener, por citar los dos autores que lideran cada una de las corrientes, no son concluyentes, toda vez que no basta con resolver la antigüedad de los textos y sería necesario referirse tanto a su difusión como a sus predecesores comunes (una aclaración más precisa puede encontrarse en Colom, 1979, apto. 1.3). Es éste un tema interesante para la Historia de la Ciencia, pero que no entorpece el objeto de este trabajo. En todo caso, es evidente que el desarrollo ulterior de ambas disciplinas se amalgama y difumina en otros rótulos más modernos como inteligencia artificial, teoría de modelos, etc... haciendo evidente la pertenencia de éstas a un mismo zeit-geist o paradigma científico.

5. A pesar de la frecuencia con la que se emplea el término retroalimentación, no parece el más adecuado. Como ya mencionara Aracil (1986), el prefijo "retro" incluye una acepción temporal que produce equívoco, pues puede leerse con el sentido de vuelta atrás, a la posición o momento inicial del proceso (puesta a cero, punto de salida), lo que no se corresponde exactamente con la naturaleza de este tipo de comportamiento. Por esta razón sólo lo mencionamos en esta ocasión y recurrimos pre- 
tan para explicar cabalmente los organismos, y en especial los superiores, se necesita el concurso de los conceptos de información, control y realimentación.

Simplificando al máximo algunos de los esquemas mostrados, podemos reducirlos a un bucle como los que muestra la figura 1 donde se representa, con ayuda de los símbolos $+\mathrm{y}-$, la diferencia entre los de realimentación negativa y positiva.

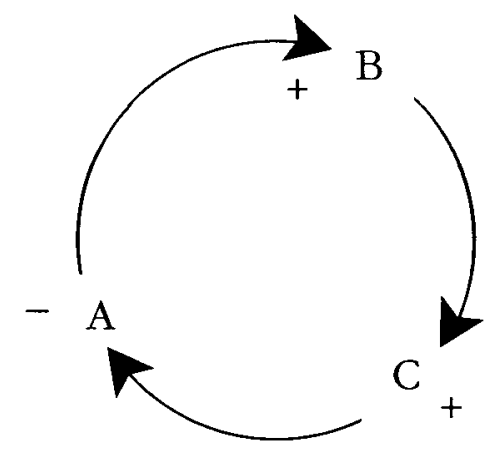

BUCLE DE REALIMENTACIÓN NEGATIVA.

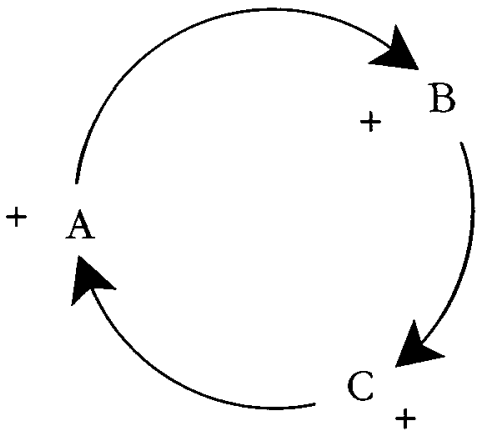

BUCLE DE REALIMENTACIÓN POSITIVA.

FIGURA 1

Es importante aclarar que aunque nos interesaremos por los dos tipos de realimentación, y muy especialmente por la combinación de ambos, nuestra preocupación se centrará en el negativo, por su estrecha relación con el comportamiento propositivo y autorregulado. En realidad, el concepto de realimentación negativa es junto a los dos de "plasticidad" $\mathrm{y}$ "correlación directiva" imprescindible para concebir y justificar el comportamiento intencional, propositivo o teleológico; y asimismo, junto al de "realimentación anticipatoria" (feed-forwad) explican el comportamiento adaptativo (conducta que se modifica como resultado de la experiencia y se refuerza selectivamente) ya en su forma simple o compleja, mediante el aprendizaje.

La realimentación positiva, por su parte, se relaciona con los procesos autocatalíticos y de crecimiento. Como se indica en el bucle correspondiente el incremento de uno de los elementos considerados produce el de los restantes y al cerrarse el círculo, un efecto recalcitrante; es el caso del crecimiento del desierto y su influencia sobre las sequías, descrito por Charney (1975). En la naturaleza son raros los sistemas dominados por este tipo de realimentación, que supone un comportamiento "explosivo", pero sí es frecuente que predominen en ciertas etapas del desarrollo y más aún, como hemos mencionado, que se presenten enlazados con bucles de realimentación negativa, como es el caso del llamado crecimiento "logístico" o "sigmodial. En este tipo de crecimiento o diná-

ferentemente al término realimentación, evitando al mismo tiempo el abuso de las expresiones inglesas (feedback, feedbefore, runaway...). A pesar de ello mantendremos la partícula "retro" en las citas textuales de los autores que lo emplean y consideraremos la idea de Sanvisens al contemplarlo como "retrotraer el efecto a la causa". 
mica aparece una primera etapa caracterizada por el crecimiento exponencial (p.e. cuanto mayor es la población mayor es su crecimiento demográfico), seguida de una etapa dominada por la realimentación negativa (las tensiones producidas por la explosión demográfica: superpoblación, hacinamiento, escasez de recursos..., fuerzan el descenso de la natalidad, la disgregación del grupo y la emigración e, incluso, el enfrentamiento). Su representación gráfica en una función población-tiempo mostraría una curva ascendente que cambiaría, a un sentido descendente, en la segunda parte de su trayectoria y en su conjunto un comportamiento sinuoso con tendencia a un eje central. Evidentemente, el ejemplo mencionado es excesivamente simple para explicar la demografía histórica, pero muestra claramente el tipo de dinámica. Un ejemplo algo más complejo pero asequible sería el gráfico de relaciones tróficas que en un biotopo se establece entre la cubierta vegetal, la población de roedores o hervíboros y sus correspondientes predadores, tal como suele aparecer en manuales de Ciencias Naturales o Ecología.

Los sistemas más sencillos de feed-back negativo son "lineales", en ellos: "el rendimiento del efector es una expresión lineal del impulso de entrada y, cuando añadimos impulsos de entrada, añadimos impulsos de salida. La lectura de salida la efectúa algún tipo de aparato también lineal. Esta lectura es una simple sustracción al impulso de entrada" (Wiener, 1985, 136). Un ejemplo sencillo de esto es un elevador de potencia o un motor eléctrico realimentado, cuya función se expresa matemáticamente en sistemas de ecuaciones lineales. Otro diseño equivalente es el termostato, tantas veces mencionado como ejemplo de realimentación.

Otros mecanismos, como un buque dirigido por un girocompás (un piloto automático), requieren al menos dos ciclos diferentes de realimentación. Lo mismo ocurre con el citado sistema de artillería antiaérea o el movimiento para coger un objeto (particularmente cuando está en movimiento) donde existe una realimentación anticipatoria que calcula la posición futura del objetivo y que acelera la realimentación del efector (ya sea cañón o extremidad). Se denomina "control mediante realimentación informativa", en donde se ha introducido una cierta cantidad de oscilaciones controladas (precisamente, para evitar un comportamiento oscilatorio grave en el sistema se introduce un elemento que crea oscilaciones en la señal eléctrica dentro de una banda definida).

En todos los casos, puede decirse que el dispositivo de realimentación de un objeto (ya sea de naturaleza artificial o social), constituido básicamente por la relación de las partes que intervienen en su funcionamiento, realiza 5 misiones:

1. La exploración del medio y la recogida de información sobre los resultados de la acción.

2. La integración de tal información en el objeto.

3. La medición (comparación) de dicha información en relación con el objetivo establecido.

4. Decidir o calcular (de forma aritmética, analógica o lógica) la corrección de las diferencias constatadas, y 
5. Transmitir las indicaciones oportunas a los órganos encargados de ejecutarlas.

Teniendo en cuenta (como se ha podido observar en algunos de los ejemplos mencionados) que estas funciones no tienen por qué corresponder a elementos $u$ órganos diferentes del objeto considerado.

Los rasgos más importantes que la presencia de realimentación incorporan a un sistema son:

1. Aumento de la exactitud.

2. Sensibilidad reducida de la razón de la salida a la entrada, a las variaciones en las características del sistema.

3. Efectos reducidos de la no linealidad y de la distorsión.

4. Aumento del ancho de banda (intervalo de frecuencias de la entrada dentro de la cual el sistema responde satisfactoriamente).

5. Tendencia a la oscilación o la inestabilidad (Distefano, Stubbern y Willians, 1981).

En general, puede deducirse que los sistemas y aparatos que cuentan con esta capacidad de autorregulación, presentan un comportamiento más eficaz (reducen errores, aminoran los procesos de ensayo-error, corrigen las desviaciones,...), relativamente autónomo ${ }^{6}$ a los cambios en el entorno y el propio sistema (dentro de unos límites razonables, aceptan alteraciones en la entrada sin modificar su funcionamiento y son capaces de corregir por sí mismos algunas disfunciones de sus propios elementos), aunque su carácter adaptativo y su apertura les obligan a una permanente búsqueda de equilibrio (homeostasis).

Nótese que no existe incongruencia entre las últimas características citadas. Los lectores habituados a los conceptos sistémicos saben bien que "estabilidad" y "dinamismo" (procesos morfostáticos y morfogenéticos) son faces indisolubles de una misma moneda. El concepto de "ultraestabilidad" da perfecta cuenta de esta relación.

Por otro lado, recuérdense algunas de las ideas ya mencionadas. El verdadero sentido de la autorregulación se encarna en el ámbito de teorías preocupadas por la explicación de relaciones causales no lineales y el comportamiento teleológico. Para Wiener, como para los primeros cibernéticos en las diversas ciencias, los mecanismos de autorregulación resultaban imprescindibles para comprender el comportamiento de entidades y seres que parecían seguir algún objetivo, inmersos en un mundo de probabilidades, ya muy alejado del espacio y el tiempo newtonianos, y que además interactúan recíprocamente con otros sistemas complejos. Es más, a estas alturas del texto se entenderá que la coincidencia de diversos auto-

6. Evidentemente, en el caso de las máquinas no es sino una pseudo-autonomía. Aunque externamente diera la sensación de control real, se trata paradójicamente de la sumisón total a instrucciones prescritas por el operador o diseñador si bien, es cierto, una vez instaladas permiten un funcionamiento "automático" (detectado el nivel, posición o situación establecido inician su ciclo de funcionamiento sin solución de continuidad). Sólo en el campo de la Inteligencia Artificial y para aquellos sistemas que cuentan con estrato de conocimiento y funciones heurísticas (Sistemas Expertos, p.e.) podría hablarse, más rigurosamente, de comportamiento autorregulativo autónomo. 
res al afirmar que los servomecanismos son a la ciencia del s. XX la "metáfora" que la palanca, el péndulo o el reloj lo fueron para otras épocas no es, en absoluto, una exageración.

En un sentido orteguiano, la metáfora —el modelo imaginativo que nos permite manejar la desconcertante y heterogénea realidad, el «como si»- del servomecanismo incluye el carácter propositivo de máquinas y organismos. En un caso, prestándoles una naturaleza pseudo-finalista, aportada por el hombre en su diseño, y en otro, explicando que el carácter finalista del comportamiento - esencial en la conducta de los seres vivos, como ya afirmara McDougall hace más de un siglopuede comprenderse de manera más racional que un extraño elemento añadido a los sistemas y seres con organizaciones complejas. La idea de concebir sistemas capaces de trasformar información, de recibir y emitir señales y utilizarlas para el control de su comportamiento, de hacer funcionar e incluso crear mecanismos autorreguladores, que tienen en cuenta su comportamiento anterior y la consecución de objetivos,... unida a las aportaciones fundamentales de Alan Turing, sobre la "morfogénesis", y Ilya Prigogine, sobre las "estructuras disipativas", está presente en casi todas las formas del pensamiento científico y tecnológico actual, rompiendo barreras entre teorías físico-matemáticas y sociales. En una descripción más general (paradigmática) entroncaría con el paradigma de la complejidad o sistémico que atiende a los preceptos de globalidad, pertenencia y teleológico (Peñalver, 1987).

Revisemos ahora algunas de las influencias más importantes en el campo de las Ciencias Sociales?.

Aunque en 1913 L. J. Henderson relacionó el ambiente interno con el externo (The Fitness of Enviroment), e influenciado por la idea hipocrática de un poder curativo de la naturaleza y por las teorías de Vilfredo Pareto, generalizó con Cannon, del que fue compañero en Harvard, el principio homeostático y lo aplicó a la filosofía social especulativa, interpretando las sociedades como organismos que desarrollan instituciones y costumbres para oponere a la perturbación de su equilibrio (Bynum, 1986) - idea central en las teorías funcionalistasWiener se mostraba escéptico, al menos en el 48, respecto a la posibilidad de aplicación de procedimientos cibernéticos al ámbito social. A pesar de las animadas propuestas, que él califica de ingenuas, de los científicos sociales con los que toma contacto -en especial el matrimonio de antropólogos Mead y Bateson-Wiener plantea restricciones metodológicas muy serias:

1. El tipo de fenómenos a los que se enfrenta la cibernética hasta el momento (físicos mecánicos o electrónicos, incluso los fisiológicos) presentan un funcionamiento consistente y una dimensión micro que permite sean estudiados e intervenidos a partir de procedimientos que se soportan en un aparato matemático de series no temporales. La aplicación de esta matemática a lo social resulta casi imposible, pues requeriría de estudios extraordinariamente largos (cuasi históricos si se desea establecer "regularidades") y de la recogida de una cantidad inmensa

7. En una versión más amplia hemos revisado la presencia de este concepto en la Matemática, las Ciencias Naturales y las Tecnológicas, pero su extensión nos impide incluirlas en este texto. 
de datos, que por otro lado difícilmente sobrepasarán un nivel de descripción meramente cuantitativo ${ }^{8}$.

2. Por otra parte, tanto la naturaleza de lo social -como objeto de conocimiento- como el carácter de las relaciones que establece el científico social con esta realidad, suponen:

- Un considerable riesgo de interpretación subjetivas (generación de "artefactos", en la terminología de investigación); definiendo ciertos factores comocausales de un proceso cuando en realidad no lo son, p.e.

- Y el problema de que la mera realización de la investigación - la presencia misma del investigador - suele influir la realidad objeto de análisis (efecto social y político de las cc. sociales), a diferencia de las investigaciones físicas que no modifican las reglas de su "universo". Hasta tal punto parece consciente de estas limitaciones que se muestra extraordinariamente crítico con ciertos intentos de presentar orgánicamente la capacidad de autorregulación natural del cuerpo social: la idea del "laissez-faire" del liberalismo económico, p.e. Incluso con la publicación en 1950 de "Cibernetics and Society", donde se muestran numerosas aplicaciones de principios cibernéticos a problemas sociales, se sigue advirtiendo su resistencia a un análisis sistemático de lo social9.

Sin embargo y a pesar de estas limitaciones, los intentos de elaborar modelos cibernéticos en el campo de la Sociología son numerosos. Es natural que así fuera cuando ya antes hubo intentos organicistas (Spencer, Durkheim,...) y mecanicistas (Pareto, Znainiecki, Sorokin y Parsons), con una pretensión similar (una "física social"), y sobre todo, si tenemos en cuenta el impacto de la Teoría General de Sistemas de von Bertalanffy en este campo. De hecho, la mayoría de los especialistas tienden a considerar que la influencia sistémica y cibernética se presentan aquí indisolublemente ligadas (Buckley, 1970; Hanken, 1981). Con estos

8. En este sentido, resulta interesante la distinción entre los procesos de realimentación "inmediata" y "secular" - tal como se expresan en Wiener, 1995-: los sistemas sociales están sometidos a eventos que transcurren en períodos de tiempo relativamente breves (de entre 1 a 10 años, p.e.), susceptibles de ser controlados y generar realimentación, pero deben contemplarse necesariamente otros procesos "seculares" de naturaleza histórica para los cuales nuestra capacidad de predicción es sumamente limitada, auque su influencia resulte indiscutible. A este respecto, ejerce una crítica sobre las políticas que dirigen tanto los planes de investigación científica como el mundo económico-empresarial, en las que se comete recurrentemente el error de establecer prospecciones a largo plazo, por simple extrapolación de los procesos inmediatos, olvidando la existencia de los seculares; limitación que considera implícita a la "ógica" del capitalismo reinante en su época.

9. En "Cibernética y Sociedad" WIENER (1969) aplica los principios de la teoría de la comunicación y la regulación a un cierto número de problemas sociales y científicos: El desarrollo de las.lenguas y su idoneidad comunicativa, el problema de la coherencia e interpretación de la Ley, el secreto y la información, la aplicación de la cibernética a la automatización industrial, el diseño de prótesis motoras y sensoriales, la posibilidad de delegar decisiones en máquinas y en general otros problemas políticos e ideológicos que afectan a la investigación científica. Destaca sobremanera el tono crítico de sus reflexiones sobre el uso de la información por el estado, la concentración y abuso de los medios de comunicación, los riesgos inherentes al desarrollo de la energía nuclear y la tecnología armamentística a los efectos perniciosos sobre el desarrollo del conocimiento de los posicionamientos maniqueos - propios de la época de "guerra fría", en la que se contextualiza-; pero, como se indicó antes, son análisis fraccionarios y sugerencias que no permiten entrever un modelo cibernétido de lo social. 
elementos - a los que habría que sumar la Teoría de Juegos y de la Informaciónse acometió un programa de investigación que pretendía: 1. definir un marco teórico capaz de simular aspectos del comportamiento de los sistemas sociales; 2. construir modelos que permitan explicar el funcionamiento interno que genera esos comportamientos; y 3. diseñar un modelo completo del sistema social (usando ecuaciones y parámetros), que sea susceptible de generar pronósticos verificables (Bustamante, 1988). La dificultad estriba en la naturaleza extremadamente abierta, compleja y característicamente morfogenética ${ }^{10}$ del sistema social. En este sentido, parece evidente que la aplicación del modelo cibernético ha supuesto la superación de los orgánicos y mecánicos - y por tanto de estructuralismos y funcionalismos clásicos- comprendiendo mejor las actividades de cambio (reestructuración, desestructuración) y relación con el medio, así como el binomio cambioconservación; pero es también evidente que ha tropezado con la dificultad -para algunos imposibilidad manifiesta ${ }^{11}$ _ de simular adecuadamente el sistema social. El caso de la autorregulación es un buen ejemplo de ello. Según Bustamante (1988, 94-95) «este mecanismo (...) se compone de cinco etapas: 1. Establecimiento de los parámetros de la meta perseguida por el sistema social y de la estrategia de acción para alcanzarla. 2. Transformación de los requerimientos de acción en actividad concreta, ya sea sobre el entorno o sobre el propio estado interno del sistema. 3. La información sobre el efecto de esta actividad retroalimenta las decisiones del centro de control. 4. El centro de control comprueba la existencia de desviación con respecto a la dirección correcta de la acción. 5. En caso afirmativo, se realizan las correcciones necesarias sobre el estado interno del sistema o la estrategia de acción... (pero) a pesar de la simplicidad y la elegancia (del modelo), su aplicación directa al terreno del análisis social se enfrenta a una serie de problemas que ponen en tela de juicio su operatividad. Buckley ha destacado algunos de ellos:

1. Resulta verdaderamente difícil señalar la existencia en la sociedad de un único centro de control, lugar privilegiado de elección de objetivos sociales y de definición de estrategias de acicón. Al postular la existencia de más de un centro decisional en el sistema social, nos veríamos obligados a multiplicar a su vez los mecanismos de autorregulación por retroalimentación. La complejidad del esquema así obtenido podría hacer inviable la construcción de un modelo operativo.

2. Tampoco está claro que las acciones más relevantes de un sistema social tengan su origen en decisiones tomadas por sus centros de control. En todo caso,

10. Los procesos morfogenéticos son aquellos que producen cambios adaptativos que implican alteraciones de las características internas del sistema, como el aprendizaje y el desarrollo en el sistema social. Por el contrario, los procesos "morfostáticos" tienden a mantener la organización del sistema, su funcionamiento explica la conservación o reducción de las desviaciones, como el papel del mito en las culturas.

11. Para algunos autores, la excesiva generalización y abstracción del modelo sistémico y cibernético impide extrapolar con validez sus principios a demarcaciones científicas concretas. Es más, algunos, como Jesús Giner (op. cit.) cuestionan incluso la cientificidad de la T.G.S. y llegan a afirmar que su propagación se debe, en buena parte, a uuna desmesurada aceptación (...) por parte de disciplinas con débil estatuto epistemológico" (p. 931). 
el modelo de retroalimentación parece poder aplicarse con más facilidad a sociedades con un grado alto de planificación centralizada.

3. El paso de las decisiones a las acciones prescritas está mediatizado por la intervención de los distintos factores sociales que se llevan a efecto. La reinterpretación que éstos hacen de las decisiones tomadas impide su traducción automática a acciones finales. Así, a la hora de la retroalimentación será difícil distinguir si la desviación fue debida a la concepción orignal de la estrategia de acción o a modificaciones ulteriores introducidas por quienes la llevaron a la práctica.

4. El retraso posible entre la acción y la manifestación de las consecuencias reales puede superar los requerimientos temporales del proceso, lo que impediría la aplicación a tiempo de medidas correctivas. El sistema tendría que decidir la ejecución de nuevas acciones sin conocer los resultados de las anteriores. Podría suceder que las consecuencias manifestadas con cierto retraso se confundieran irremediablemente con las acciones ulteriores, perdiendo así la referencia necesaria para la retroalimentación del sistema".

Como es fácil comprender, las limitaciónes y restricciones expuestas, tan comunes en el campo de las reformas políticas, no afectarían igual a los sistemas más pequeños, altamente organizados y centralizados, que actúan en relación con proyectos de duración no muy larga. Esta razón explica el uso generalizado del modelo en los métodos de planificación y estrategias que suelen aplicar las organizaciones empresariales a los grupos de investigación.

En todo caso, conviene aclarar que el uso del concepto realimentación no se limita exclusivamente a la consecución eficaz de metas (praxiología). En este ámbito, el concepto de realimentación incorpora, muy especialmente, el sentido de "autodirección". Para ello se requiere de tres tipos de información: la que procede del entorno (del exterior), la del pasado (acumulación de la experiencia) y la del propio sistema (de su composición y estructura).

Dependiendo del tipo de información a procesar, se distinguen tres clases de realimentación:

- la "persecución de metas", producida por los datos nuevos procedentes del entorno, cuando no cambian las operaciones internas;

- el "aprendizaje", cuando los nuevos datos del entorno modifican el funcionamiento y estructura del sistema, alterando su memoria y experiencia; y

- la "conciencia", cuando la realimentación surge de nuevos datos internos que informan sobre los cambios en su composición y estructura (Giner, 1988).

Un proceso parecido al descrito - que en todo caso podría generalizarse al campo de las ciencias sociales- es el que se ha producido en el ámbito de la Economía. En particular nos interesa reseñar, por la importancia concedida a los procesos de realimentación, la Dinámica de Sistemas (Aracil., 1978). En una descripción muy simple, puede considerarse un procedimiento de construcción de modelos de sistemas económicos, o sociales, que pretende al mismo tiempo esclarecer su estructura y funcionamiento interno y permitir simulaciones del comportamiento del sistema cuando es sometido a ciertas condiciones hipotéticas. Debe añadirse, para su mejor comprensión, que estos objetivos exigen, por su propia naturaleza, un esfuezo considerable dirigido a explicitar tanto los principios teóricos 
que fundamentan el modelo, como las relaciones que se establecen (o se desean probar) entre los elementos significativos del sistema. Esta exigencia obliga a expertos en dinámica y en el tipo particular de sistema social considerado a formalizar y argumentar de forma muy precisa ciertas ideas claves, así como a revisarlas regularmente en la medida en que los resultados de la simulación en el computador difieran del comportamiento real conocido del sistema. Esta virtualidad, aunque no es exclusiva de dicha técnica, se presenta con un grado mayor de exigencia que en otros procedimientos analíticos y, desde luego, que en la mayoría de los estudios denominados de "caja negra"; y es más interesante aún, al considerar que se trabaja con sistemas "blandos". Naturalmente, en este contexto son muchas las dificultades y limitaciones que se presentan, pero los resultados desde el surgimiento de esta disciplina en los años 50, inicialmente aplicados al mundo industrial (dinámica industrial), y más tarde en los 60 a los problemas urbanos (ha tenido una considerable repercusión en la Geografía Urbana y Comercial), desembocó en una consolidación de las técnicas y en su generalización a otros tipos de problemas (además de su importante influencia en el urbanismo, se han utilizado para el estudio de problemas sociales como la difusión de la drogodependencia, los sistemas comerciales e, incluso, la difusión de ideas políticas y religiosas). La aplicación de los trabajos de Forrester $(1969,1970)$, autor central en este campo, al análisis de la problemática planetaria que realizó el Club de Roma (Meadows, et al., 1972) es suficientemente significativa. Su plausibilidad en los análisis a medio y largo plazo ha permitido una cierta complementariedad con las técnicas de la Econometría tradicional. Interesa resaltar aquí que en los modelos dinámicos de Forrester el concepto de realimentación es central. En primer lugar como condición básica para el dinamismo del sistema. Después, por su presencia masiva como elemento constitutivo de todos los sistemas económicos y sociales (en general de forma compleja: estructuras de "segundo orden" donde se enlazan ciclos de realimentación positiva y negativa). Y, finalmente, porque la mayoría de los problemas que se abordan tienen que ver con la generación de retrasos en la información en los ciclos de realimentación (lo que produce comportamientos oscilatorios y disfuncionales, como ya sabemos) o la ignorancia de las relaciones entre estos ciclos, que impide la adecuada comprensión de los orígenes del problema, muchas veces producidos por la estructura misma del sistema, más que por motivo de ciertas acciones coyunturales como pudiera parecer, haciendo así inútiles cuando no contraproducentes ciertas medidas de control o desfigurando la relación causal en el tiempo con similares resultados.

Otro ámbito del conocimiento en el que el concepto de realimentación ha tenido presencia es el de la Antropología cultural, si bien rastrear su presencia aquí resulta más complicado. Resulta evidente que desde el surgimiento de los estudios históricos-culturales, comandados por la figura de Franz Boas, y más claramente desde la perspectiva funcionalista (M. Mauss, B. Malinowski,...) se defiende la idea de que los sistemas culturales presentan algún grado de autorregulación. Esta capacidad se explica en procesos de adaptación y asimilación muy diversos ${ }^{12}$ diri-

12. Así por ejemplo, Martínez Veiga (1985) recoge en su análisis del concepto "adaptación" cuatro acepciones no excluyentes del término: adaptación calculativa o racional, bomeostática o de retro- 
gidos a objetivos concretos como el mantenimiento de la cohesión del grupo, la elaboración de rituales para la conservación de las tradiciones autóctonas y la división secular de clanes,... y, en general, la reproducción de los rasgos de identidad étnicos. En este sentido, y también para los estructuralistas como C. Lévi-Strauss, existe una función autorreguladora en el pensamiento mítico y el rito (Prat, 1985; Rappaport, 1987). Ahora bien, a pesar de la aceptación más o menos generalizada de esta idea, no es fácil encontrar descripciones más precisas de los procesos en los que se realiza. Es cierto que existen análisis detallados de ciertos hechos muy significativos (la incorporación de objetos y personajes foráneos como símbolos asimilados a los cultos "cargo", p.e.), pero estas descripciones no especifican el modo en que se relacionan operativamente fines y métodos de control y ajuste, aunque quede implícito en su contexto. Existe sin embargo un campo de investigación muy importante en la actualidad en el que - probablemente por la influencia de los modelos procedentes de la Biología - se ha estudiado minuciosamente los procesos autorregulativos: la Antropología ecológica. En la medida en que se parte del etudio de las relaciones entre sistema cultural y sistema ecológico en el que está inmerso (la cultura como estrategia adaptativa al entorno) o las interaciones recíprocas entre ambos, se han venido desarrollando una serie de explicaciones procesuales que contemplan mecanismos de realimentación negativa y positiva en los que se entrelazan fenómenos tecnológicos, condiciones materiales, estructuras conductuales y mentales, producción de energía, reproducción demográfica, etc... El "neofuncionalismo ecológico" de Rappaport y Vaida, el "materialismo cultural" de Harris y los modelos procesuales de los 80 , incluyendo la ecología de sistemas y la de poblaciones, son buenos ejemplos de esta perspectiva (Sánchez Fernández, 1986). En todo caso, es necesario indicar que, si bien la aplicación de estos conceptos ha esclarecido bastante algunos tópicos de la antropología - como los modelos de coste-beneficio al problema de la territorialidad-, distan mucho de permitir la formulación de leyes generales. Añádase que la preminencia de la perspectiva "eti"13 en este tipo de estudios les ha granjeado la enemistad manifiesta de gran parte de los antropólogos contemporáneos.

En lo que a la Teoría de la Comunicación se refiere, las implicaciones del término realimentación pueden comprenderse a varios niveles jerárquicos y desde distintos puntos de vista, algunos de los cuales ya se han mencionado al hablar de las aplicaciones cibernéticas a otras disciplinas. Por un lado, desde planteamientos matemático-formales aplicados al procesamiento de información y, en

alimentación, progresiva o madurativa y evolutiva o poblacional. En este mismo trabajo, propone ejemplos de realimentación cultural en los que intervienen aspectos genéticos, económicos, tecnológicos y rituales; y distingue entre estrategias (comportamientos conscientes, individuales, inmediatos) y procesos de adaptación (inconscientes, colectivos, en largos períodos de tiempo, por acúmulo de estrategias) que son los que estudian observadores y antropólogos, claramente vinculados a los fenómenos de realimentación.

13. Cuando en la descripción etnográfica prevalece el punto de vista del investigador, la tendencia a la objetivación, la verificación intersubjetiva apoyada en modelos externos o generales se denomina "etic" (de fonético); cuando, por el contrario, se pretende dar la palabra al nativo, a la elaboración subjetiva,... se denomina "emic" (de fonémico). 
particular, a su implementación en sistemas artificiales de comunicación, la cuestión de la realimentación se vincula a problemas relativos a la optimización de la transmisión y decodificación de la señal, capacidad intrínseca de los códigos, modelos probabilísticos, uso de la redundancia y limitaciones de los sistemas para la reducción de los ruidos y otros fenómenos que alteran el mensaje. Desde este campo, se ha demostrado que "la capacidad de cualquier aparato o sistema como regulador no puede sobrepasar su capacidad como transmisor de información" (Ashby, 1984, 107), por ejemplo. En este nivel, los fenómenos de realimentación utilizados son típicamente de "feek-back negativo", esto es, por corrección del error por un "regulador" - ya sea estático o dinámico- que mantiene el sistema en equilibrio haciendo uso de las transformaciones regladas y previstas por el sistema: "cambios de nivel 1" en la terminología de Watzlawick (1980)14.

En las versiones más interesadas en la comunicación humana - ya sea verbal o no- los procesos de realimentación han sido descritos en relación con los actos comunicativos:

- tanto en sus aspectos individuales sincrónicos, como posibilidad de adecuación al objetivo lingüístico (regulación de los ruidos y oscilaciones del sistema comunicativo, control de la redundancia), una tendencia dinámica de carácter aleatorio y discontinuo, lo que dificulta su formalización matemática (Sanvisens, 1984);

- cuanto en su aspecto dialógico y comunitario, en el que juega un papel clave al explicar cómo los interlocutores en el intento de producir o mantener el acoplamiento se ven forzados a reconstruir-desconstruir sus respectivos códigos (o versiones individuales de los mismos), reducir o integrar la divergencia, recurrir a metalenguajes que permitan la reificación de los niveles inferiores,... y en suma, poner en juego sus programaciones, sus rituales e incluso su ideología. No en balde, y más allá de los aspectos sintácticos y semánticos, se ha caracterizado al "diálogo" -el verdadero nivel "Comunicativo", en su sentido etimológico, de los sistemas de comunicación- como un proceso dinámico y activo que requiere de la empatía, la apertura y respeto a las posiciones del otro, génesis y resultante de las actitudes democráticas.

Nótese cómo el acceso a este nivel de estudio supone un verdadero salto cualitativo en relación con los precedentes. No sólo se incorpora la significación, la semántica, lo connotativo-valorativo, sino la proxemia, la comunicación como conducta social humana, intencional basada en un proceso cooperativo de interpretación en que los participantes se refieren simultáneamente a algo en el mundo objetivo, en el social y el subjetivo, como ha puesto de manifiesto J. Habermas (1988). No es de extrañar por lo tanto que ciertos términos adquieran así una nueva significación o valor. Si la redundancia, por ejemplo, era la relación entre

14. Para Watzlawick los cambios en el sistema presentan dos niveles posibles: En el nivel 1 el cambio es de un estado a otro, esta transformación permite mantener estable los niveles superiores y el equilibrio del sistema. Son propios de la realimentación negativa como se ha mencionado. En el nivel 2, los cambios son de transformaciones, es decir, de los tipos o estilos de comportamiento del sistema y se relacionan con los procesos de realimentación positiva, como más tarde veremos. 
la información máxima teórica de un mensaje, salida de una fuente dada, y la información real emitida, transmitida y decodificada (Escarpit, 1977) o lo que es lo mismo, el grado de inutilidad de un signo, factor de ineficacia a corregir en un sistema de comunicación, ahora se convierte en una condición necesaria y positiva para la eficacia de la comunicación humana. Del mismo modo, los procesos de realimentación incorporan los de signo positivo: cuando las perturbaciones recibidas del medio (o del sistema con el que se acopló) no pueden ser neutralizadas, desplazando al sistema de sus parámetros y produciendo inestabilidad, se genera un proceso de desorganización, pero que potencialmente puede venir seguido de un período de reorganización - los cambios de nivel 2 de Watzlawick-. Así las cosas, la desorganización producida por las perturbaciones en los sistemas abiertos con capacidad de auto-organización es la que justifica el mantenimiento de las relaciones con el medio, su pervivencia y la estabilidad misma del sistema en un sentido global. Hablamos entonces de crecimiento, adaptación, construcción, especialización y optimización de los sistemas; procesos que requieren en todo caso de los diversos tipos de realimentación (Marce, 1990).

Las primeras explicaciones cibernéticas ${ }^{15}$ en el campo de la Psicología se refieren a las investigaciones de Paulov sobre el reflejo condicionado y plantean la posibilidad de comprenderlo (analógicamente) como un circuito de feedback en el que los refuerzos aumentan la probabilidad de ocurrencia de una conducta aprendida (condicionada) - una concepción muy similar se amplía a los mecanismos de la evolución natural-.

Les interesa en particular el sistema "afectivo" - pero en el sentido de placer-displacer, p.e.- y mostraron, ya en la década de los 40 , un interés muy peculiar por la posibilidad de transmisión de información relevante para este sistema por vía no neuronal: citan explícitamente las hormonas en relación con el aprendizaje.

Es importante reseñar que la aproximación que los cibernéticos realizaron a la psicología, al menos al inicio, se hizo desde una posición estrictamente "neuro" y "psicofisiológica", en gran parte basada en el convencimiento de que la psicología tradicional, mentalista e incluso conductual (para ellos, digamoslo, prácticamente pre-científica), se esclarecería en el futuro por reducción a su soporte físico, neuronal o bioquímico.

A pesar de ello, resultaría muy precipitado acusarles de biologicistas, teniendo en cuenta que su visión "interrelacional" del mundo les condenaría, más tarde o más tempano, a establecer relaciones causales complejas entre "imágenes-percepciones-redes neuronales-engramas mnésicos", por ejemplo ${ }^{16}$. Tanto es así que,

15. Esto es, desde la teoría ya constituida, pues ya antes Lorente de No (1922), Forbes (1929) y Ranson y Hinsey (1930) habían trabajado sobre la reverberación central y las cadenas reverberantes de neuronas, con ideas muy similares (Fuentes, J. B. y Robles, F. J., 1988; Taton, R., 1988).

16. Parece sin embargo que algunos psicofisiólogos modernos se resisten a plantear relaciones causales de este tipo y muestran una "sospechosa" preferencia por explicar la conducta como efecto de causas biológicas. No es que renieguen de modelos de causalidad recíproca, es que sus trabajos experimentales muestran, mayoritariamente, una clara tendencia a explicaciones unidireccionales de 
en los primeros escritos existen ya significativas menciones a modelos psicoterapéuticos dinámicos en concordancia con explicaciones cibernéticas —es verdad, que muy arriesgadas-. Con el trascurso de los años, parece evidente que la incorporación de las concepciones y modelos cibernéticos a estos campos de la psicología más próximos a los niveles biológicos del comportamiento, ha resultado muy fructifera. Otra cosa, sin embargo, cabe decir de las escuelas de orientación cognitiva. En este ámbito, el desarrollo de modelos analógicos y simulaciones ha tenido un desarrollo inusitado, pero ha venido acompañado de duras críticas epistemológicas, en particular centradas en el problema de la "metáfora del ordenador". Aunque Wiener siempre fue muy prudente respecto a la analogía del computador, ya en 1943 W. S. McCulloch y W. Pitts presentaron un modelo cibernético del cerebro. A partir de las analogías mencionadas entre neurona y circuitos eléctricos y de los trabajos de Shanon sobre operaciones lógicas en estos últimos, se hizo posible la aplicación del álgebra de Boole (sistema binario) a modelos electrónicos que simularían el procesamiento de la información que se produce en el cerebro. Nacen así distintas líneas de trabajo: Inteligencia Artificial (dearrollo de sistemas artificiales que se comportan de un modo "inteligente", imiten o no las operaciones mentales humanas) y Simulación (cuyos circuitos sí deben respetar ciertas restricciones propias de los humanos, como el tiempo de reacción, p.e.), con distintas vinculaciones con la psicología del procesamiento de la información y las neurociencias. Ahora bien, tanto unas como otras parecen adolecer de graves limitaciones, ya sean relativas a la capacidad lógica de los sistemas programados sobre lenguajes simbólico-matemáticos para resolver problemas relativamente triviales para la inteligencia humana, ya por la práctica imposibilidad de asumir el carácter de conciencia en una máquina, etc. ${ }^{17} \ldots ; \mathrm{y}$, en general, como afirman Fuentes y Robles (1988), por reducir — por la aplicación de lenguajes formalesla comunicación a pura sintaxis, evitando así el problema de la significación y, al tiempo, olvidando la experiencia y la acción, elementos esenciales del comportamiento humano. Claro está, que estas críticas no son sino una etapa más en la polémica que, más tarde, será alterada por la posibilidad de introducir o variar otras perspectivas del cognitivismo desde posiciones genetistas - J. Piaget- o evolutivas $-\mathrm{K}$. Lorenz $\mathrm{z}^{18}$ - y, más recientemente, con el reposicionamiento de la Psicología Cognitiva en planteamientos más naturalistas y experimentales ${ }^{19}$. En todo caso, no parece que la aplicación del concepto de realimentación, ya sea en

la clase atipo morfológico, función fisiológica o neurológica, tasa hormonal o de neurotransmisores, etc. $\rightarrow$ incide, implica, produce $\rightarrow$ comportamiento, normal o patológico".

17. Respecto a la primera limitación es clásico la imposibilidad de superar el Teorema de Gödel, como indicó J. R. Lucas (1961); en cuanto a la conciencia y las máquinas vid. M. Scriven (1953), ambos en respuesta al "Maquinaria computadora e inteligencia" de TuRING, A. M. (1950), y todos ellos recogidos en la edición de Ross, A. (1984): Controversia sobre mentes y máquinas. Tusquets, Barcelona.

18. Para una visión más actual de las corrientes cognitivas, vid. Varela, F. J. (1990).

19. Una revisión crítica de los modelos formales, computacionales (Turing, Fodor, Pylyshyn...), que reducía pensamiento a "procesamiento de la información", ha llevado a los psicólogos cognitivistas a recuperar, desde puntos de vista más fenomenológicos y experimentales, la concepción de la mente e inteligencia humanas caracterizadas por la intencionalidad, significación y conciencia. Una interesante descripción de la situación actual puede leerse en Rodríguez Santos, J. M. (1995). 
su versión más operativa, ya en su comprensión más profunda (teleológica, evolutiva, etc...) este en entredicho. Esto significa, conviene recordarlo, que la definición operativa de la realimentación —en su versión psicológica- no se reduce a su traducción formal-simbólica, por muy esclarecedora que resulte (puede ser analizada cómodamente en algoritmos idénticos a los mencionados para los lenguajes de programación), sino que sigue siendo válida cuando se refiere al proceso de interación entre realidades, imágenes y esquemas mentales, interpretaciones lingüísticas y, más aún, cuando se relaciona con componentes intencionales de la mente. Un ejemplo, entre otros, de lo dicho podría ser los modelos cibernéticos de la personalidad (Tizón, 1973).

Un buen ejemplo de ello son las teorías sobre el "autocontrol" y el desarrollo de las técnicas de "autodirección", ligadas a éstas (Capafons, 1981). Aunque en las primeras aportaciones de Skinner (1969) se definía el autocontrol como un tipo específico de conducta que reducía la posibilidad de emitir otra conducta que sería castigada - resolviendo así el conflicto entre consecuencias positivas (inmediatas) y aversivas (a corto o medio plazo) - se consideraba, en todo caso, como un comportamiento (aprendido) regido por la influencia ambiental (control del estímulo, restricción o ayuda física a la respuesta, control de contingencias...). Fue más tarde, con la aproximación desde una óptica cognitiva, cuando el comportamiento autocontrolado empezó a tomar un carácter de regulación verdaderamente autónoma ${ }^{20}$, en la medida que se consideraba como una respuesta ante situaciones conflictivas mediada por procesos cognitivos superiores, como el pensamiento y el lenguaje. Así, Goldfried y Merbaum $(1973,12)$ lo definen como "una decisión a la que se llega a través de una deliberación consciente con el propósito de integrar una acción que está designada a lograr ciertos resultados deseados u objetivos, determinados por el sujeto mismo"; aunque debe aclararse que, en su contexto, esta definición no excluye en modo alguno la interacción con el medio que actúa «ab inition, introduciendo nuevas informaciones, por la ausencia de control externo inmediato..., y que sigue presente por la "promesa" de recompensas diferidas (la alabanza social a la resistencia a la tentación, p.e.). Es precisamente en esta influencia indirecta del medio, donde las mediaciones cognitivas tienen un peso determinante a la hora de explicar el cambio de probabilidad de una respuesta (Thoresen y Mahoney, 1974). En el mismo sentido, Kanfer (1976, 1977) entendía el autocontrol como un tipo especial de autorregulación, lo consideraba como un procedimiento autocorrector para resolver discrepancias, índices de peligro inminente o estados motivacionales conflictivos. En su modelo inicial, el proceso comprendía tres etapas: Autoobservación (Self-monitoring), establecimiento de criterios y autoevaluación (Self-evaluation) y autorefuerzo (Self-reinforcement); y se distinguen dos tipos elementales de autocontrol: el "decisional" — cuando el sujeto elije entre la alternativa de consecuencias inmediatas y la de consecuencias diferidas de mayor

20. Debe matizarse: relativamente autónoma, pues las mediaciones cognitivas no son endógenas, su origen se encuentra en el aprendizaje social, pero una vez constituidas (son relativamente estables) actúan con valor deliberativo y motivacional, inclinando el "locus" de control hacia el sujeto y, en este sentido, favoreciendo una mayor independecia del medio. 
valor, pero deja de tener control sobre los resultados- y el "prolongado", variante del anterior - en el que además de tomar la decisión debe poner en práctica estrategias y recursos para lograr el objetivo-. En cuanto a las técnicas de autodominio o autodirección desarrolladas en este ámbito y sólo a efectos de enumeración cabe citar por grandes grupos: Programación del entorno (control del estímulo físico, cambio del entorno social, restricción del estímulo y control del mismo por medio de variables fisiológicas), Cambios de los repertorios comportamentales, Métodos de automanejo (autoobservación, autoevaluación, contratos de contingencias, modelado y autorrefuerzo), así como otras técnicas cognitivas de aplicación al caso (aprendizaje autoinstruccional, solución de problemas, etc...) (vid. A. Capafons, J. L. Castillejo, et. al., 1985). En cualquier caso - y para los autores citados y otros relevantes en el tema como A. Bandura y su Teoria del Aprendizaje Social (1983) - y a pesar de reconocer al autocontrol como una meta social, tiende a considerarse como un comportamiento definido, pero no como un rasgo general de la personalidad ${ }^{21}$. Será necesario remitirnos al ámbito pedagógico y a su relación con la Autonomía para estudiar esta posibilidad.

Resulta evidente que las primeras aplicaciones o adaptaciones de los conceptos cibernéticos al campo educativo se integraron en el nivel de análisis correspondiente a los procesos de enseñanza y aprendizaje, y esto por varios motivos. Es claro que los modelos explicativos de las cadenas comunicacionales se adaptan fácilmente a la relación docente-discente, y, más generalmente, a cualquier forma de interacción educando-educador. Este tipo de interacciones, en particular las características del Sistema Formal por su intencionalidad explícita, su formalización y referencia a contenidos curriculares, pueden someterse a procedimientos y técnicas muy estructuradas como los algoritmos (Landa, 1978) y otras interpretaciones muy ligadas a la instrucción (Frank y Meder, 1976; Von Cube, 1865, 1981). De otro lado, la concepción más funcional y operativa de la educación como proceso semejante, basado en o solapado al de aprendizaje - un campo en el que los términos información, regulación, optimización..., habían sido adoptados con éxito- facilitaban igualmente su generalización, aún en el caso de advertir que el interés preferente en este ámbito se cifrara en los denominados aprendizajes superiores ${ }^{22}$.

Pero existe una cibernética bumana - $\mathrm{O}$, mejor aún, «humanista»- de mayor calado. Es aquélla que no se conforma con una mera trascripción de ciertos términos al campo educativo, o con la incorporación necesaria de los datos experimayor.

21. Algunas corrientes actuales de la psicología parecen otorgar al autocontrol una imporancia

En algunos casos el concepto de realimentación se ha convertido en central, como pasa con la denominada Programación Neuro-Lingüística (PNL), Sugestopedia y otras corrientes terapéuticas o de asesoramiento (counseling), pero no han sido tratadas aquí por cuanto no pueden considerarse nuevos modelos teóricos. Es común a las que acabamos de citar un cierto carácter de aglomerado o amalgama de técnicas (parece que muy útiles en la resolución de ciertos problemas y en formato de terapia breve) cuya integración no parece bien resuelta. Nada de extrañar cuando los creadores de alguna de ellas reconocen abiertamente haberlas diseñado por la selección de procedimientos de muy variado origen y el criterio de efectividad de los terapeutas de las que las han tomado.

22. En los que "...intervienen integradamente aspectos cognitivos, afectivos y volitivos y en (los) que se desarrollan capacidades de orden superior, específicamente humanas. Patrones sociales y cul- 
mentales prodecentes de disciplinas vinculadas (Biología, Psicología, Teoría de la Comunicación...), sino que trata de esclarecer hasta qué punto la aplicación de la perspectiva cibernética puede ser un aparato conceptual adecuado a la naturaleza del fenómeno educativo en todas sus dimensiones (intrapersonal, comunicativa, sociocultural), lo que significa justificar, no sólo aspectos metodológicos, también los teóricos: congruencia con las perspectivas o niveles de descripción y comprensión antropológica, teleológica, social,... Es esta perspectiva la que nos interesa y a la que nos vinculamos; y, es evidente, ya se anunció al comienzo del texto, que se personifica en la figura del Dr. Sanvisens y la escuela de colaboradores que repetidamente se referencian.

Desde esta perspectiva, hablar de autorregulación y, en su versión educativa de control/eficacia/optimización y autocontrol/autonomía, es tanto como desentrañar una de las condiciones sine qua non para afirmar la educación como proceso evolutivo de construcción y liberación.

En primera instancia, como procedimiento para racionalizar la acción educativa y asegurar mínimamente su eficacia. Es verdad que el término "control" se ha ido cargando de significaciones peyorativas (represión, uniformización,...) — como, entre otros, ha puesto de manifiesto Sarramona (1990)_, pero, no es menos cierta la posibilidad de una lectura positiva —como indica él mismo, retomando las conceptualizaciones de Wienner, Couffignal o Chadwick y Rojas 23 - que incluiría necesariamente la consideración del educador como regulador del comportamiento del educando, así como la del educando como sujeto autorregulado. Así, "Hetero y autocontrol constituyen dos fases que, en buena lógica de una concepción dinámica del proceso, donde se alcanzan progresivos estadios de autonomía, han de ser consecutivas, sin que resulten contradictorias con la concepción tecnológica. La educación aparece así como un proceso gradual, que en un principio toma la forma de una modificación simple de conducta basada en patrones socioculturales, pero va adquiriendo formas muy evolucionadas y complejas". (Sanvisens, 1984, 23). Concepción dinámica a la que, necesariamente, debe sumarse el respeto e interés por las diferencias individuales (tanto en lo referido a las condiciones iniciales de procesos - nivel de configuración actual, dominio de códigos, ... - como en lo teleológico - aceptación y gestión de lo multicultural, elaboración de mínimos consensuados, desarrollo de la función crítica, etc...-; como bien ha puesto de manifiesto Castillejo (1985)24).

turales, símbolos abstractos, generalizaciones de la mente, propósitos voluntarios y planificados, ideales de conocimiento y de acción, normas de conducta individual y social, modelos teóricos y prácticos resultados de la creación humana, proyectos culturales, principios operativos de gran complejidad, planes prospectivos... podrían servir de pauta o de objetivo para dicho aprendizaje. Intervendría en el mismo, o podría intervenir, un plano de voluntariedad, de esfuerzo, de seguimiento consciente y, especialmente, de afectividad o emotividad, característico del conocimiento y de la acción, en definitiva, del proceder humano. Sería, pues, un aprendizaje integrativo, estructurador, posiblitador de una experiencia consciente". Sanvisens, 1983, 163.

23. "Sistemas y procedimientos aptos para asegurarse que la realización de un plan sigue las normas establecidas" Chadwick y Rojas (1978, 80), citados por Sarramona $(1990,81)$.

24. Argumentando el carácter singular y radicalmente personal de la Educación, el autor, recuerda que la búsqueda de una "matriz" educativa común — que no clónica- está condicionada por la 
Es precisamente el problema de Autocontrol/Autonomía uno de los lugares donde más claramente se percibe la intención liberadora del modelo, ya que se concibe la autonomía como categoría antropológica y, por ende, objetivo inexcusable de la Educación (Capafons, Castillejo, et al., 1985). Se retoma aquí la dimensión antropológica (Oñativia, 1978) que distingue los niveles de estructuración de la información y códigos que presentan los sistemas vivos (también en su perspectiva filogenética: Lorenz y Wukettis, 1984). Se diferencia entre:

- los mecanimos desencadenadores innatos, cuyo código se puede denominar "autorregulación": presentes en las formas vivas más elementales y que aparecen en el Hombre en diversos niveles (desde los procesos neurovegetativos y los reflejos hasta ciertos patrones de respuesta más complejos; Eibl-Eibesfeldt, 1977), ligados al mantenimiento del equilibrio (homeostasis) y a la regulación adaptativa,

- y los mecanismos adquiridos de conducta, por vía del aprendizaje individual, y que van: desde los procesos de "acomodación" o "autoacomodación", como reacción condicionada, en niveles preconscientes o "raciomorfos" 25 (Riedl, 1983), al control de "Sí mismo" o "autocontrol", ya puramente racional, exclusivamente humano, por lo que supone de consciente, cognitivo y ligado al sentido, los valores y metas.

Estos últimos incluirían en la tipología propuesta por Sanvisens (1983 a, 1984 a,...) los niveles y funciones de la regulación/optimización proyectiva e introproyectiva $y$, en un sentido general suponen, no sólo la posibilidad de aprender habilidades y estrategias capaces de asegurar o inhibir ciertos comportamientos y aumentar la eficacia en la realización de tareas concretas, sino la de influir educativamente sobre el sujeto para favorecer su independencia respecto al entorno, aumentar su autoconocimiento y responsabilidad (Capafons, Castillejo, et al., 1985; Castillejo, 1987 b). Inevitablemente estas últimas condiciones se vinculan a criterios axiológicos (Thorpe, 1980) y en la medida en que implican elaboración de consistencias, generalización/transferencia de habilidades, disposiciones en el comportamiento (actitudes) vinculadas a valores, permiten hablar de la Autonomía como un verdadero eje de la personalidad del sujeto, sobrepasando así la consideración del autocontrol psicológico como ya mencionamos.

Por cierto, que en este orden de descripción es importante resaltar que la realimentación, así entendida, sobrepasa ampliamente el concepto de bomeostasis. Una de las críticas a la concepción cibernética de la educación es aquélla que pre-

recepción y percepción estimular diferenciada, la reintegración de los efectos de la conducta, la adscripción a cosmovisiones diversas, la variabilidad situacional y la inclusión de procesos de optimización proyectiva,... lo que refutaría en esencial las visiones exclusivamente "reproductoras" de la Educación (y aún del Sistema Educativo Formal), restringiendo la discusión a cuestiones sobre los condicionantes sociales del proceso como más o menos favorecedores/inhibidores de cambio/reproducción.

25. En los experimentos con antropoides se ha mostrado que esta conducta raciomorfa contempla relaciones causales simples de tipo "si-entonces", una cierta apertura a la consciencia de la propia existencia y pertenencia social y local. 
tende reducirla, precisamente, al concepto de homeostasis. Se afirma la idea de que, desde esta concepción, el problema se reduce a comprender al hombre como "Otra" máquina más, capaz de reaccionar ante perturbaciones externas con el fin de recuperar su equilibrio (Hamann, 1992). Es cierto que se acepta que este comportamiento se refiera a ciertos objetivos, así como que la complejidad del medio humano suponga una permanente ruptura y búsqueda de la homeostasis. Pero no es menos cierto que, asimilándola a las concepciones psicoanalísticas (endogenismo, lo anímico como motor del comportamiento) reducen la cuestión, al convertir la capacidad de autorregulación en un fin en sí mismo. La homeostasis, así entendida, responde solamente a ciertas pulsiones naturales o programaciones individuales y no se vincula con objetivos de mayor entidad 26 . Vistas así las cosas, sólo queda realizar una crítica "humanista", tildar tal interpretación de mecanicismo reduccionista y salvar al Hombre de la Cibernética recordándonos sus capacidades espirituales, su dimensión social, su altruismo y ansia de libertad. Ahora bien, queda por demostrar que la cibérnetica humana sea incapaz de proponer una descripción que supere los aspectos meramente equilibradores y de eficacia de la regulación. Muy por el contrario, su interés se cifra en los aspectos evolutivos - la regulación se encuentra indisolublemente ligada a la optimización del sistema y, en los sistemas superiores y desde luego en el Hombre, esto conduce a procesos morfogenéticos de crecimiento y maduración (así, la homeostasis, nunca es la recuperación del equilibrio perdido; es sólo la superación provisional, por su propia naturaleza, de un estadio en el proceso de perfeccionamiento. De ahí la preferencia por el término "homeorhesis"27)_. Parte de la base de que los procesos autorregulativos se producen con referencia a patrones o modelos adquiridos -naturalmente del entorno social y cultural-y que se realizan en la interacción

26. Es posible que tal confusión proceda de la siguiente secuencia. El interés inicial de la cibernética se centró particularmente en sistemas físicos no humanos. Al apelar a los principios físicos que regulan las redes de relaciones causales, se hizo posible definir el comportamiento teleológico sin necesidad de apelar a una causa final. De este modo, se liberaba a estos sistemas de una interpretación antropomórfica, como indicaron Rapaport y Horwoth. La cuestión es que al volver la mirada hacia el Hombre se utilice la misma explicación no-antropomórfica, lo que naturalmente daría resultados ridículos. Afortunadamente, muchos cibernéticos fueron conscientes de este posible error y desarrollaron una línea humanística del modelo; $y$, por cierto, sin necesidad de "forzar" ninguno de los conceptos claves.

27. Si la homeostasis persigue un objetivo de constancia (conseguido éste se establece una relativa inactividad del sistema), la homeorhesis se refiere a objetivos variables o cambiantes que generan un nuevo nivel de resolución (Waddington, 1976, citado por Sanvisens, 1983). En realidad, desde la T.G.S. (Bertalanffy, 1981, cap. VIII) y la Cibernética (Canon, 1932) siempre se tuvo claro que el principio de la homeostasis u homeostasia, en sentido estricto, no se podía aplicar a regulaciones dinámicas, actividades espontáneas, procesos que tienen como meta el establecimiento - y no la reducciónde tensión o el crecimiento. Explícitamente, se afirma como inadecuada para la explicación de las actividades humanas no utilitarias y se critica el uso desmedido de este concepto en el ámbito de las relaciones sociales, sujetas a valores culturales. Aunque no van a ser tratadas aquí, las explicaciones más satisfactorias en relación con el comportamiento teleológico vendrán de la mano de E. Morin (1981), N. Luhman (1983) y H. S. Simon (1979), que en sus conceptualizaciones sobre endo-causalidad, mundo exterior y lo existencial coinciden en explicar el comportamiento verdaderamente finalista como emergencia de la complejidad de la organización viva (Peñalver, 1987). 
con el medio, que se ve manipulado y afectado por la conducta (Sanvisens, 1983, 1987 b). No queda claro entonces, al menos en mi opinión, quien genera el reduccionismo 28 .

Buena prueba de ello es la especial atención que, desde esta perspectiva, han recibido la realimentación proyectiva e introproyectiva. La primera (también llamada feed-before, realimentación anticipatoria, en este contexto) como mecanismo propio de los organismos con capacidad de aprendizaje y memoria individual y social que les permite proyectar su experiencia en el futuro. Este nivel de adaptación complejo es el que explica cómo, ante las alteraciones desconocidas del medio, los sujetos aplican y seleccionan de su repertorio de comportamientos las soluciones más plausibles y comprueban sus resultados. La selección por comparación, valoración y síntesis del contexto/situación, reconfiguración perceptiva, generalización y transferencia y otros procesos bien conocidos, justifican su valor adaptativo, al tiempo que permiten considerarlo como un proceso individual, activo (muy lejos ya de los automatismos de respuesta) e irrepetible; cuya explicación y pronóstico se somete a leyes probabilísticas y explicaciones idiosincráticas, resultado del momento/estado de configuración en la biografía del sujeto. Indisoluble con los procesos de reconfiguración (reducción de la disonancia, personalización, moldeamiento, ajustes, optimización de procesos, inhibición y extinción de comportamientos inadecuados,...), el otro lado de la adaptación, lo que permite predicar la educación como jerarquía de autorregulaciones que entraña procesos de innovación y cambio ${ }^{29}$. No podía ser de otra manera, salvo que se

28. No es anecdótico que un buen número de críticos al modelo sistémico-cibernético (y, por extensión, al tecnológico) centren sus argumentaciones en la consideración de éste como mera analogía mecánica (tecnicista) o económica (Taylorismo), exenta de consideraciones filosóficas y morales e incapaz de incorporar ciertas categorías antropológicas (creatividad, crítica, conciencia) o sociales (disensión, conflicto, representación y participación democrática,...) Queda por ver, si estas lecturas fraccionarias no son resultado de un sesgo interesado.

Es cierto, que en una primera etapa, el interés por los aspectos metodológicos y aplicados —en la mayor parte de las publicaciones- sobrepasó con mucho a las facetas teleológicas y axiológicas que, aunque presentes, quedaron en penumbra — sumémosnos a la crítica-; pero no es menos cierto que la "arquitectura conceptual" del modelo incluyó, desde el principio, elementos como los mencionados - proyección, interiorización, evolución,... establecimiento y validación de patrones, negociación,...-. Podría replicarse que tales elementos no son sino añadidos: esto es, una argucia dialéctica con la que resolver las carencias y lagunas detectadas por los críticos. Peor si atendemos a las fuentes (reléase de nuevo los textos de Sanvisens en su cronología) y el origen interdisciplinar de los conceptos (genética, epistemología, lingüística,...), no parece sostenerse tal posibilidad. Otras cuestiones son las relativas a una lectura desde la Sociología o la Historia de la Ciencia - a qué posiciones ideológicas interesa el modelo, de qué teorías desciende-, pero, tampoco ahí esta claro que la cosa se reduzca a una vinculación exclusiva al conductismo skinneriano, el taylorismo empresarial y el "accountability", como se ha sugerido. Menos aún, cuando forma parte de un paradigma, lógicamente, más amplio (incluiría, entre otras líneas, modelos genetistas y constructivistas, cognitivos, ecológi$\cos , .$. ). En cuanto a una crítica de rango gnoseológico, el autor confiesa no haberla encontrado, ya sea por sus propias limitaciones.

29. Es sabido que incluso para la Creatividad, las explicaciones sustentadas en la intuición, divergencia, imaginación,... - en especial cuando no se aclara la génesis de tales procesos- como únicos elementos, no han sido capaces de dar cumplida cuenta de tal aptitud. Las teorías más avaladas en actualidad $-\mathrm{y}$ que han permitido el desarrollo de programas educativos, generales o específicos- 
desee vincularse a determinismos biológicos o sociales o se esté dispuesto a aceptar el cierre del sistema con la tendencia entrópica que acarrea.

A los niveles descritos se sumaría, en la cúspide ${ }^{30}$, las regulaciones vinculadas a la conciencia y los valores:regulación introyectiva. Se trata ahora de esa estructura auto-organizadora que provee al Hombre de la conciencia de sí mismo y de su actividad, de la existencia de su memoria y su corporeidad en un nexo indisoluble, la que accede a la teoría y la argumentación, la que genera la esperanza y la angustia, la que le convierte en objeto y sujeto de su conocimiento,... la que se asienta en su desarrollado encéfalo pero no se justifica en éste; antes, al contrario, parece explicar su actual conformación. Muchas veces puesta en duda por los experimentalistas y siempre esperanzadamente afirmada por los educadores, hoy de nuevo en el centro de las Ciudades Humanas (Popper, Bunge, Morin, Ashby, Piaget, Lorenz, Thorpe y un larguísimo etcétera lo consideran central en sus teorías). Algo más compleja que un epifenómeno que no puede observarse más que por sus resultdos; escurridiza al tacto positivista, presencia evidente para los humanistas.

Extraño objeto para un tecnólogo... pero familiar y necesario. Falsa paradoja sin embargo, pues sólo la autoconciencia completa la visión total de nuestro sistema. Otorga unidad al complejo caleidoscopio de nuestra personalidad y nos explica convincentemente la naturaleza cultural del Hombre. Es este proceso de autorregulación, capaz de redefinir los patrones últimos de referencia del sistema, el que permite el autoconocimiento y, en su expresión más completa, el autodominio: manipular nuestras propias variables para modificar favorablemente las entradas, imaginarnos/representarnos para modificarnos ${ }^{31}$. Su relación con la creatividad personal (Sanvisens, 1982 b, 1983; Puig, 1987 a y b), la función crítica (Cervera, 1984), la especialización como autopoiesis, autoestructuración (Castillejo, 1987), los aprendizajes de nivel III y IV de Bateson (Martínez Martín, 1984)..., pone

incluyen necesariamente la memoria, facilidad de adaptación, la constancia, un alto grado de estructuración cognitiva y especialización, así como referencias al cálculo de la utilidad, idoneidad y valor de los resultados como factores esenciales. Tampoco las ideas relativas a la innovación social y cultural sin referencia al conocimiento e interpretación del presente y pasado gozan de gran predicamento, si excluimos las versiones más inicuas del postmodernismo.

30. Es evidente que la concepción jerárquica tiene un sentido filogenético, ontogenético y de valor, pero no debe leerse sino como superposición de niveles entrelazados: la adquisición de un nivel superior no elimina ni obstaculiza la acción de los inferiores, a los que esta ligado funcionalmente. De hecho es común encontrar descripciones y gráficos en los que la jerarquía se presenta como circuitos entrelazados de realimentación. Así, por ejemplo, lo hace el Prof. Puig Rovira $(1987,131)$ que superpone un $2^{\circ}$ circuito de feed-back que al recibir información tanto del medio como del "detector" del $1^{\circ}$, actúa — cuando el $1^{\circ}$ se muestra insuficiente- sobre éste, modificando sus objetivos. Esto es, hace posible la verdadera evolución perfectiva, por la modificación de los mecanismos y comportamientos adaptativos -incluido los objetivos más inmediatos ligados al equilibrio y la eficacia-, en función de patrones personales y sociales. Al mismo tiempo, y siempre que se reduzca la demora en la corrección, que protege al sistema de un comportamiento oscilatorio grave por reacción a los cambios bruscos del ambiente; o lo que es lo mismo, introduce una cierta distancia con el medio, favoreciendo un comportamiento más autónomo.

31. Aunque no interesa aquí, es necesario recordar que tales procesos también tienen su lado patológico (el "autoengaño", p.e.) del que la psiquiatría ha dado buena cuenta. 
de manifiesto su trascendencia. El hecho de que requiera métodos de análisis más formales, fenomenológicos, cualitativos o que se ajuste con más dificultad al grafismo al uso, no es óbice para predicar su existencia. Por lo demás es claro que a este nivel se encuentran los fines más valiosos de todo proceso educativo: aquéllos que se refieren a la construcción y desarrollo de personalidades autónomas, sujetos libres e integrados en su realidad social e histórica (Castillejo y Colom, 1987). En este sentido, el auxilio de las nuevas concepciones científicas (en particular, la concepción tecnológica) en la comprensión y regulación de este proceso (la educación), no rompe el continuo histórico, en lo que a las finalidades propuestas por las teorías educativas (teleología) se refiere.

\section{CONCLUSIONES}

En primer lugar, no debe olvidarse que tanto el concepto general de sistema como todos los relacionados con éste - y, en particular, los de realimentación y control- no dejan de ser modelos formales de interpretación de la realidad. A pesar de lo obvio de la afirmación (básicamente, todos los conceptos científicos lo son, aún los pertenecientes a las terminologías de las disciplinas más positivas), es necesario recordarlo. Tal cosa no debe sin embargo interpretarse como una limitación inconveniente, antes bien debe recordarnos la importancia que la proyección de tales ideaciones apriorísticas tienen sobre la interacción con la misma realidad (el mundo III de Popper). En este sentido, recuérdese que la aplicación de perspectivas sistémicas ha colaborado significativamente a la superación de teorias que reducían la educación a la mera adaptación al medio físico/biológico (lamarkismo, Demmor y Jonckeere, Claparade), al objeto de conocimiento (empirismo) o los factores ambientales (sociológicos - Durkheim - o culturales —endoculturación-), y al mutacionismo, el vitalismo creacionista, el idealismo y espiritualismo pedagógico, en el extremo opuesto (Puig, 1987 a).

Segundo. El breve recorrido histórico realizado y la constatación de la importante presencia del concepto de autorregulación en muy diversas ciencias permite afirmar su bondad como adecuado útil conceptual para el objeto y fin de la Pedagogía. Particularmente, por su calidad de herramienta adecuada para vérselas con las realidades complejas y dinámicas, por ajustarse a los procesos no lineales, la causalidad circular, la ordenación jerárquica y relacional de los sistemas y niveles y, muy especialmente, a los sistemas humanos. Aunque, como ya hemos señalado, esta virtualidad no debe llevarnos a soluciones simples, de mero préstamo lingüístico. La integración del término autorregulación (y todos los asociados a él que mencionamos) se ha realizado respetando los requisitos de congruencia, precisión y adecuación a nuestro objeto específico. Al menos, por los autores referidos. Desgraciadamente, no podríamos aseverar otro tanto para el uso más coloquial de los profesionales ${ }^{32}$.

32. Es sabido que no somos la única profesión en la que ciertas modas en el lenguaje cunden, a tal extremo, que se convierten en coletillas y frases hechas. El empleo superficial, cuando no inade- 
Tercero. Que como hemos querido demostrar en el último apartado, el uso del concepto autorregulación es adecuado tanto para los niveles y procesos integrados en el sujeto humano, como para las relaciones educativas y ciertos aspectos de la Educación, en su vertiente social.

Cuarto. En relación con los primeros se presenta un cuadro resumen en el cuadro adjunto. Aunque dicho cuadro pretende mostrar de la manera más clara posible los muy diferentes niveles en los que los procesos de autorregulación estarían presentes, se muestra insuficiente a la hora de expresar la emergencia de los niveles más elevados y su relación con los inferiores. En opinión del autor, este aspecto quedaría perfectamente resuelto con la lectura de "El enfoque sistémico de la conciencia" del Prof. Puig (1978 b), antes citado. En este trabajo se describen los mecanismos y procesos mentales involucrados. Se consideran tres niveles:

I. Conjunto total de las relaciones técnicas, comunicativas y expresivas que se dan entre el individuo y su medio.

II. Representación y modificación mental de una parte al conjunto total de las interrelaciones individuo-medio.

III. Conocimiento o saber de las propias representaciones o modificaciones mentales, que acaba permitiendo la aparición de un yo autoconsciente (p. 238), y se explican las relaciones entre éstos y los procesos de representación y modificación que culminarían en el proceso siempre inacabado de la autoconstrucción y autodirección.

\begin{tabular}{|c|c|c|}
\hline Genético. & $\begin{array}{l}\text { Fisiología celular. Proceso antagónico donde } \\
\text { intervienen: realimentación positiva (operador), } \\
\text { que activa el proceso, y negativa (represor), } \\
\text { que lo inhibe. Intervención del ADN y ARN. }\end{array}$ & $\begin{array}{l}\text { Procesos de síntesis de las } \\
\text { proteínas, encimáticos,... }\end{array}$ \\
\hline
\end{tabular}

Embrionario. Sucesión de procesos de realimentación que generan cambios morfogenéticos en el embrión, originando nuevas estructuras.

"Inducción biológicaw: configuración del tronco, de la cabeza, de tejidos y órganos especializados.

Reflejos.

Circuitos neuromusculares. Innatos. Pertenecientes al Sist. simpático. Mayoritariamente resueltos a Reflejo "miotáticon y todos aquéllos nivel medular (ganglionar). Regulación inmediata o muy rápida (milésimas de seg.). En general, feedback negativo, salvo desajustes patológicos ("clonus", p.e.). habituales en el diagnóstico pediátrico o neurológico que permiten la valoración de la madurez y estado general del sistema.

Vegetativo. Feedback negativo. Más lentos. Intervención de órganos y hormonas.

Posibilidad de aprendizajes: Biofeedback.

Mecanismos reguladores de la tensión arterial, regulación hepática, etc... Control voluntario de ciertos procesos fisiológicos neurovegetativos.

cuado, de ciertos términos y explicaciones vulgarizadas prestan escaso favor a la propagación de innovaciones teóricas. Introducir en gráficos y modelos una flecha recursiva que enlace al final y el principio para indicar que se trata de un proceso continuo, sensible de algún modo a sus resultados, sin explicar el valor y sentido de las interacciones se convierte en una práctica espuria. 
Sensoriomotor.

Voluntarios. Finalistas. Sist. parasimpático. Intervención niveles superiores (S.N.C.).

Aprendizajes básicos y de supervivencia.

Aprendizajes superiores I.

Aprendizajes superiores II.
Adaptativos. De regulación guiada por objetivos "externos". Más o menos preconscientes, con intencionalidad difusa (influencias informales), que tienden a ser explícitamente intencionales y progresivamente autónomas. Primeros niveles de socialización/enculturación. Procesos imitativos, reforzamientos, condicionamiento, modeling,... en los que prevalece la asimilación del entorno. En sus aspectos más elementales aun participan de este nivel otras especies animales.

\section{Control anticipatorio (feed-before),} optimización/ regulación proyectiva: Personalización/ Especialización, consistencia en conductas y tendencias. Intencional y consciente. Prevalece en lo posible, adaptación/control del ambiente en función de metas y expectativas.

Claramente, nivel antropológicco. No "activadas" por el S.N.C. aunque se resuelvan en él. (No reducibles a explicaciones fisiológicas).

\section{Regulación/optimización introyectiva:} Autoconocimiento (el yo como sujeto y objeto del conocimiento, con carácter autorganizador del mismo) "Consciencia” y "sentido" (valorativo, axiológico). Elaboración/reelaboración de patrones personales.
Conducta psicomotriz (gruesa, fina): bipedalismo,... (Patolog.: temblor intencional, tabes dorsal,...).

Aprendizaje de códigos lingüísticos y gestuales, normas de comportamiento, niveles básicos de habilidades sociales, hábitos, rutinas y estrategias cognitivas básicas, moral heterónoma,...

Conocimiento abstracto.

Reelaboración personal de

estrategias, mapas,... cognitivos.

Adscripción

consciente al "zeist-geist", cosmovisiones, patrones culturales. Moral autónoma. Actitudes. Autocontrol, responsabilidad,...

Autonomía. Función crítica. Creatividad.

Quinto. Para las relaciones educativas, en su sentido funcional, son de aplicación todos los conceptos, normas y tecnologías desarrolladas en la Teoría de la Comunicación. Esto incluye adecuaciones precisas a contextos como la enseñanza no presencial, el uso y efectos educativos de los medios de comunicación de masas y la incorporación de las nuevas tecnologías de la comunicación (Colom, 1993; Sarramona, 1986 a, 1986 b, 1988; Vázquez, 1986, 1993; Ortega y Martínez, 1994,... por citar los más próximos). Estas teorías específicas recogen no sólo los mecanismos de control de la eficiencia del sistema y las estrategias de reconducción necesarias, sino también las concreciones a los niveles de realimentación anticipatoria (feedbefore): así, por ejemplo, Sarramona (1990, 82-83) cita la planificación de opciones abiertas, tanto para los objetivos (optativos y libres), como para el uso los recursos y dominio de contenidos. Dichas técnicas incorporan: pruebas de autoevaluación de tipo abierto y aplicado que se acompañan de instrucciones generales de verificación; preguntas que dirigen al educando a reflexiones y no a respuestas concretas; y actividades sugeridas para llevarse a cabo en contextos diversos. 
Sexto. También en el campo de la programación y organización educativa ha tenido sus repercusiones. Desde los ya lejanos trabajos (UNESCO, 1979) en el diseño de microsistemas a los desarrollos de modelos parciales centrados en la gestión educativa, prospectiva y política educativa. Debe reconocerse sin embargo que, en estos modelos "macro", los intentos han sido más modestos y su repercusión mucho menor (problemas sobre la demanda educativa, financiación, pronóstico del resultado de reformas a corto plazo, etc...). Así lo demuestran las tendencias imperantes en el ámbito de la Política Educativa (Colom, 1994). Como ya se comentó en los párrafos dedicados a la Sociología y la Economía, la dificultad de modelar tales sistemas, dirige los esfuerzos al planteamiento de hipótesis circunscritas a fenómenos y efectos específicos no muy bien conocidos. Algo parecido ocurría en el ámbito de la Prospectiva, donde el concepto de regulación y los métodos de investigación ligados a él tienen una presencia significativa (Sanvisens, 1897 a).

Séptimo. Una visión más optimista permite los desarrollos relativos al control del producto educativo y al control social de la educación. El primero en cuanto a la proliferación y perfeccionamiento de métodos de control del producto, control de calidad, tecnologías del outpt: cada día más capaces para detectar tanto los efectos previstos, deseados o no, como los no previstos (Castillejo, $1987 \mathrm{~b}$ ); en sus dimensiones individuales y sociales, inmediatas y mediatas (De la Orden, 1984); a través de multitud de metodologías, capaces de contemplar desde los efectos cognitivos hasta los actitudinales. Tal control se resuelve en los ámbitos o niveles de los patrones (técnicas de reconocimiento y derivación de patrones), elaboración y realización de la intervención educativa (técnicas de decisión, optimización, aplicación de la teoría de juegos,...), de los efectos educativos (evaluación), de sanciones (inhibición, facilitadoras, generalización y transfer,...), etc... Sobra decir, que todas ellas se dirigen, no tanto a sus efectos sancionadores como, a los de realimentación y optimización de la acción educativa.

Octavo: En lo que al control social de la educación se refiere - en especial del Sistema Educativo Formal - la consideración de ésta como subsistema ya presupone la posibilidad de control externo. Con independencia de la clásica polémica "educación como factor de reproducción vs. factor de cambio" (que, en buena medida, quedaría superada por la consideración de la causalidad compleja), resulta evidente la necesidad del control democrático sobre aquellas funciones que se encarga al sistema educativo. Así lo establece la legislación (para el Estado Español es referencia obligada de Ley Orgánica del Derecho a la Educación) y así lo consideran multitud de autores cuando se refieren a la responsabilidad de los educadores y centros con respecto a la comunidad, el usuario y la burocracia (Elliot, 1989), ya sea en lo reltivo a la selección del Patrón, como a los resultados. Sería deseable sin embargo que las medidas conducentes a favorecer y asegurar la representación de todos los estamentos -en los Consejos Escolares, p.e.- fueran acompañadas de procedimietos racionalizadores de su actuación. No se trata de introducir más técnicos - aunque sí sería deseable una cualificación específica de algunos de los profesionales representados-, racionalizar no es "pedagogizar" la sociedad. Se trata más bien de establecer procedimientos y estrategias de acción, incluso rutinas de trabajo, que aumentan la claridad y eficacia en el trabajo de control. 
Noveno. Por lo que al control interno se refiere, ya ha quedado dicho al hablar del autocontrol. Añadiremos aquí que en su consideración de objetivo educativo se han mostrado eficaces las técnicas de control ambiental, de modelado, de autodirección, de decisión, de efectos controlados, de auto-observación, simulación y previsión de efectos (Capafons, et al., 1985).

Décimo. Creo, humildemente, que estas páginas recogen de forma suficiente la significación e importancia de los fenómenos de autorregulación. Es claro, sin embargo, que todo ello debe vincularse con el sentido que se le dé a otros términos de su red nomológica (adaptación, optimización, equifinalidad, emergencia, teleología, teleonomía...) y que aquí solo se han apuntado. Sus vinculaciones con dichos conceptos pueden esclarecerse adecuadamente recurriendo a la bibliografía citada. Un estudio más exhaustivo sobre las últimas aportaciones a esta temática (Morin, Simon, Luhman, entre otros) mostrará hasta qué punto, y a pesar de lo que se ha avanzado desde los trabajos de Maxwel, es todavía hoy una cuestión en desarrollo.

\section{BiBLIOGRAFÍA}

ARACIL, J. (1978): Introducción a la dinámica de sistemas. Alianza Universidad, Madrid.

- (1986): Máquinas, sistemas y modelos. Tecnos, Madrid.

Ashby, W. R. (1956): Introducción a la cibernética. Nueva Visión, Buenos Aires.

- (1965): Proyecto para un cerebro. Tecnos, Madrid.

- (1987): "Sistemas y sus medidas de información", en VON BERTALANFFY, L.; Ross AsHBY; WEIMBERG, G. M. et al. (1984), 95-117.

AzNAR, P. (1987): “Entropía-Negentropía: Análisis e implicaciones educativas", en AA.VV. Conceptos y propuestas IV. Papers d'Educació, Nau-Llibre, Valencia.

Bandura, A. (1983): Teoria del Aprendizaje Social. Espasa-Calpe, Madrid.

Bertalanffy, L. Von (1976): Teoría General de los Sistemas. Fondo de Cultura Económica, México.

- (1986): Perspectivas en la teoria general de sistemas. Alianza, Madrid.

Bertalanffy, L. Von, Ross Ashby, Weimberg, G. M. et. al. (1984): Tendencias en la teoria general de sistemas. Alianza, Madrid ( $3^{\text {a }}$ ed.).

BuckiEY, W. (1970): La sociologia y la moderna teoria de los sistemas. Amorrortu, Buenos Aires.

Bustamante, J. (1988): "Sociocibernética", en Reyes, R. (Dir.): op. cit., 92-95.

Bynum, W. F. (1986): "Homeostasis", en Bynum, W. F.; Browne, E. J. y Porter, R. (Dir.): Diccionario de bistoria de la ciencia. Herder, Bardelona, p. 298.

CANNon, W. B. (1932): The Wisdom of the Body. W. W. Norton Co. New York, citado por BERTALANFFY (1981): op. cit.

Capafons, A. (1981): Bases Teóricas y Experimentales del Autocontrol. Universidad de Valencia.

Capafons, A., Castillejo, J. L. et al. (1985): Autocontrol y Educación. Nau-Llibres, Valencia.

CASTILlejo, J. L. (1985): "Educación y acción educativa (segundas aproximaciones), en AA.VV.: Conceptos y Propuestas II. Papers d'Educació. Nau-Llibres, Valencia.

- (1987 a): Pedagogía Tecnológica. CEAC, Barcelona.

- (1987 b): "Control, Autocontrol y Educación", en CASTillejo, J. L. y Colom, A. J. (1987): op. cit., pp. 201-215. 
Castillejo, J. L. y Colom, A. J. (1987): Pedagogia sistémica CEAC, Barcelona.

CERvera, A. (1984): "Educació, Antropología y Función Crítica", en AA.VV.: Conceptos y Propuestas (I). Papers d'educació. Nau Llibres, Valencia.

CHADWIK, C. y ROJAS, A. M. (1978): Glosario de Tecnologia Educativa. O.E.A., Caracas.

Charney, J. G. (1975): "Dynamics of deserts and drought in the Sahel", en Quart. J. Roy. Meteor. Soc., 181, 193-202, citado por LIONS, J. G. (1990): El Planeta Tierra. El papel de las matemáticas y de los ordenadores. Instituto de España, Espasa Calpe, Madrid.

Colom, A. J. (1979): Sociología de la educación y teoría general de sistemas. Oikostau, Barcelona.

- (1982): Teoria y metateoría de la educación. Trillas, México.

- (1986): "Pensamiento tecnológico y teoría de la educación", en AA.VV.: Tecnología y Educación. CEAC, Barcelona, pp. 13-30.

- (1993): "La educación como comunicación", en VARIos: Teoría de la Educación. Taurus, Madrid, pp. 59-79.

— (Edit.) (1994): Política y Planificaciōn Educativa. Preu Spínola, Sevilla.

Couffignal, L. (1970): La Cibernética. A. Redondo, Barcelona.

Coufrignal, L. et al. (1968): Cibernétida y aprendizaje. Grijalbo, México.

CuBE, F. von (1965): Kybernetiscbe Grundlagen des Lermens und Lebrens. Ernst Klett Verlag, Stuttgart.

- (1981): La Ciencia de la Educación. CEAC, Barcelona.

De LA ORden, A. (1984): "El producto de la educación y su evaluación", en AA.VV.: Conceptos y propuestas I. Papers d'Educació. Nau-Llibres, Valencia.

DisTeFano, STUBbERnd y Wildians (1981): Retroalimentación y sistemas de Control. SchaumMcGraw-Hill, Madrid.

EIBL-EIBESFELDT, IL. (1977): El hombre preprogramado. Alianza Universidad, Madrid.

Elurot, J. (1989): Práctica, recerca i teoria de l'educació. Eumo, vic (Barcelona), citado por SARRAMONA (1990): op. cit.

ENGLERT, L. et al. (edits.) (1986): Lexicon der kibernetischen pädagogik und der programmierten instrucktion. Quickborn B. Hamburg.

EsCARPIT, R. (1977): Teoria General de la Información y de la Comunicación. Ecaria, Barcelona.

ForRester, J. W. (1969): Urban Dinamics. MIT, Press, Cambridge (Mass).

- (1970): World Dinamics. MIT, Press. Cambridge (Mass).

FRANK, H. G. y MEDER, B. S. (1976): Introducción a la Pedagogía Cibernética. Troquel, Buenos Aires.

Fuentes, J. B. y Robles, F. J. (1988): "Psicocibernética”, en Reyes, R. (Dir.): op. cit., 85-92.

Ganascia, J. G. (1994): La inteligencia Artificial. Debate, Madrid.

GEORge, F. H. (1979): Fundamentos de cibernética. Pirámide, Madrid.

Gimeno, J. (1982): La pedagogía por objetivos. Obsesión por la eficiencia. Morata, Madrid.

GINER, J. (1988): "Sistema Social", en REYEs, R. (Dir.): op. cit., 930-933.

GOLDFRIED, M. R. y Merbaum, M. (Eds.) (1973): Bebavior bcange trough self-control. Holt, Rinehart and Winston, New York, citado por CAPAFONs, A. (1981): op. cit.

Gullbaud, G. T. (1955): La Cybernétique. P.U.F. Paris [trad. cast. "La Cibernética", 1956. Vergara, Barcelona, traducción, introducción y notas de A. Sanvisens].

HaBermas, J. (1988): Teoría de acción comunicativa. Taurus, Madrid.

Hamann, B. (1992): Antropología Pedagógica. Vicens Vives, Barcelona.

HANken, A. F. G. (1981): Cibernetics and Society. Tunbridge Wells, Kent.

(C) Ediciones Universidad de Salamanca

Teor. educ. 8, 1996, pp. 95-128 
HARRIS, M. (1982): El materialismo cultural. Alianza, Madrid.

KANFER, F. H. (1970): Self-regulation: research, issues and especulations. En NeuRINGER, G. y MichaEl, J. L. (Eds.): Behavior modificacion in Clinical Psychology. Appleton, New York.

- (1976): The many faces of self-control or behavior modification changes its focus. $8^{\mathbf{a}}$ International banff conference. March. USA. Traducción castellana en Análisis y Modificación de conducta, 1978, vol. 4, 5, 11-16.

- (1977): Self-Regulation and Self-Control. En ZeIzER, H. (Ed.): The psychology of the 20th. Century. vol. 4 from classical conditioning to bebavioral tebrapy. Kindler-Verlag. Zurich, citados por CAPAFONS, A. (1981): op. cit.

LANDA, L. N. (1962): "Sobre el enfoque cibernético de la teoría del aprendizaje», en Voprosi filosofii, 9 .

- (1972): Cibernética y Pedagogía. Labor, Barcelona.

- (1978): Algoritmos para la enseñanza y el aprendizaje. Limusa-Trillas, México.

LANGley, L. L. (1982): Homeostasis II. Alhambra, Madrid, (2 $2^{\underline{a}}$ ed.).

LORENZ, K. y WuKETTIS, F. (1984): La evolución del pensamiento. Argos Vergara, Barcelona.

LuCAS, J. R. (1961): "Mentes, máquinas y Gödel”, en Philosophy, vol. XXXVI, recogido en Ross, A. (1984): op. cit.

LuHMAN, N. (1983: Fin y Racionalidad en los Sistemas. Editora Nacional, Madrid.

MaNnHEIM, K. (1958): El hombre y la sociedad en la época de crisis. Leviatán. Buenos Aires, citado por Rodríguez NEIRA, T. (1992).

MARCE, F. (1990): Conducta y Comunicación. Una perspectiva sistémica. PPU, Barcelona.

MARGalef, R. (1978): Perspecticas de la teoria ecológica. Blume, Barcelona.

Martínez Martín, M. (1984): Aprendizaje y Educación, en Sanvisens, A. (1984 b): op. cit., pp. 87-111.

- (1987): "Dimensiones adaptativas y proyectivas de los sistemas", en CAStillejo, J. L. y Colom, A. J. (1987): op. cit., pp. 221-233.

Martínez Veiga, U. (1985): "Cultura y adaptación", en Cuadernos de Antropología, 4 (monográfico).

Maruyama, M. (1976): "The second Cybernetics: Desviation-Amplifyng Mutual Casual Processes", en Buckiey, U. (Comp.): Moderne Systems Research for the Behavioral Scientist. Aladine P.C. Chicago, pp. 304-313.

Matilla, M. J. (1993): Máquinas y Capitalismo. EUDEMA. Madrid.

Maxwell, J. (1868): "On Governors", en Bellman, R. y Kalaba, R. Comp. (1964): Selected papers on mathematical trends in control theory. Dover, citado por ARACIL (1986).

MCCulloch, W. S. y PITTS, W. (1943): "A Logical Calclus of the Ideas Inmanent in Nervous Activity", en Mathematical Biolphysics, 5, 115-133.

Meadows, D. H. et al. (1972): Los limites del crecimiento. F.C.E., México.

MoRín, E. (1981): El Método, Cátedra, Madrid (2 vol).

MülleR, D. D. (1976): Kybernetische Pädagogik. Werbegemeinsschaf und Meurreur, Berlin.

Neuscholosz, S. M. (1939): Análisis del conocimiento científico. Losada, Buenos Aires (2 $2^{\mathrm{a}}$ ed.) [citado por SANVISENS: 1956 a].

Newman, J. R. (1975): Pensamiento y máquinas. Grijalbo, Barcelona.

Ortega, P. y Martínez SÁnchez, F. (1994): Educación y Nuevas Tecnologías. Cajamurcia, Murcia.

Oñativia, O. V. (1978): Antropología de la conducta. Guadalupe?, Buenos Aires.

Pavlov, I. 1982): Fisiología y Psicología. Alianza, Madrid (7ª ed.).

PEÑALVER, C. (1978): “Las explicaciones sistémicas: Una aproximación a la epistemología sistémica", en CASTILlejo, J. L. y Colom, A. J. (1987): op. cit., pp. 45-57.

POPPER, K. R. ECCLES., J. C. (1980): El yo y su cerebro. Labor, Barcleona. 
Prat, J. (1985): La mitologia i la seva interpretació. La Llar del Llibre/Els llibres de la Frontera, Barcelona.

PRigogine, I. (1983): ¿Tan sólo una ilusión? Una exploración del caos al orden. Tusquets, Barcelona.

Prigogine, I. y Stengers, I. (1979): La novuelle alliance. Gallimard, Paris.

PuIG, J. J. (1987 a): Teoría de la Educación. Una aproximación sistémico-cibernética. PPU, Barcelona ( $2^{\mathrm{a}}$ ed.).

— (1987 b): "El enfoque sistémico de la conciencia”, en Castrulejo, J. L. y Colom, A. J. (1987): op. cit., pp. 236-245.

Pushkin, V. N. (1974): Psicología y Cibernética. Planeta, Barcelona.

RAPPAPORT, R. (1987): Cerdos para los antepasados: El ritual en la ecología de un pueblo de Nueva Guinea. Siglo XXI, Madrid.

REYES, R. (Dir.) (1988): Terminlogía científico-social. Aproximación crítica. Anthropos, Barcelona.

RIEDL, R. (1983): Biología del conocimiento. Labor, Barcleona.

RoDríguez NeIRA, T. (1992): "Algunas formas de racionalidad. El problema educativo", en Teoría de la Educación, vol. IV, 73-89.

- (1994): "Contradicciones de la cultura", comunicación al XIII Seminario Interuniversitario de Teoría de la Educación, Tarragona, Dic. Documento policopiado.

Rodríguez SANTOS, J. M. (1995): "El lenguaje: piedra de toque par la ciencia cognitiva", en MarTínez-Freire, P. F.: Filosofía y Ciencias Cognitivas. Suplemento no 3 de Philosophica Malacitana.

Rose, J. (1977): La revolución cibernética. Fondo de Cultura Económica. México.

Rosenblueth, A., WiENER, N. y Bigelson, J. H. (1943): "Behavior, purpose and teleology", en Pbil. Scien, X, 18-24.

Ross, A. (Ed.) (1984): Controversia sobre mentes y máquinas, Turquets, Barcelona.

SÁNCHEZ FERNÁNDEZ, J. O. (1986): “Modelos procesuales en antropología ecológica y económican, en Agricultura y Sociedad, 40, 99-124.

SANVISENS, A. (1956 a): "Estructura de lo real. Teoría de la función y del grupo", en Tesis. Revista Española de Cultura, 6, 13-25.

- (1956 b): "Los problemas de la cibernética", incluido en el libro de Guilbaud, G. T. (1956): op. cit.

- (1959): "La transcendencia del automatismo", en Espiritu, 8, 153-64.

- (1968): "Cibernética y comunicación", en AA.VV.: Sociología de las relaciones públicas. Instituto de Ciencias Sociales de la Diputación de Barcelona.

- (1970): "Algunos aspectos de la Cibernética y de la Sociología Lingüística". Ponencia, recogida en SANvisENS, A. (1984).

- (1976): "Cibernétida del aprendizaje", en AA.VV.: Crítica y porvenir de la Educación. Sociedad Española de Pedagogía, Madrid.

- (1982 a): "Dimensión cibernétida del aprendizaje de adultos". Educar., 1, pp. 7-14.

- (1982 b): "Cibernética de la creatividad”, en Innovación Creadora, 14-15, pp. 175-186.

- (1983 a): "Concepción Sistémico-cibernétida de la Educación", en AA.VV.: Teoría de la Educación I. El problema de la educación. Límites, Murcia.

- (1983 b): "Cibernética y educación", en Diccionario de Ciencias de la Educación. Santillana, Madrid, vol. I, pp. 242-47.

- (1984 a): Cibernética de lo bumano. Oikos-tau, Barcelona.

- (1984 b): Introducción a la Pedagogía. Barcanova, Barcelona.

- (1986): "Teoría cibernética de la acción", en AA.VV.: Tecnología y Educación. CEAC, Barcelona, pp. 33-51. 
- (1987): "Concepción sistmémico-cibernética de la educación", en Castillejo, J. L. y Colom, A. J. (1987): op. cit., pp. 109-131.

Sarramona, J. (1984): "Tecnología y Educación", en SANVISENS (Dir.) (1984 b): op. cit., pp. 199-225.

- (1986 a): "Sistemas no presenciales y tecnología educativa", en VARIOS: Tecnología y Educación. CEAC, Barcelona, pp. 103-124.

- (1986 b): "Tecnología apropiada en educación", en QUIPU, 2. O.E.I. Madrid, pp. 4-5.

- (Dir.) (1988): Comunicación y Educación. CEAC, Barcelona.

- (1990): Tecnologia Educativa. (Una valoración crítica). CEAC, Barcelona.

Simon, H. A. (1952): "Comments on the theory of organization", American political Science Review, 46, 1130-1139.

- (1979): Las ciencias de lo artificial. ATE, Barcelona..

SKInNeR, B. F. (1969): Ciencia y conducta bumana. Fontanella, Barcelona.

Taton, R. (dir.) (1988): Historia General de las Ciencias. Orbis, Barcelona, vol. 12. El siglo XX. I. Las matemáticas. En especial, Cap. IX "La cibernética" de F. Le Lionnais.

Thoresen, C. E. y Mahoney, M. J. (1974): Behavioral Self Control. Holt, Rinehart and Winston. New York, citado por CAPAFOns, A. (1981): op. cit.

TORPE, W. H. (1980: Naturaleza animal y naturaleza bumana. Alianza, Madrid.

TIZÓN, J. L. (1973): "Modelos cibernéticos de la personalidad", en Teorema, vol. III/4, citado por Martínez, M.: Dimensiones adaptativas y proyectivas de los sistemas, Catillejo, J.

L. y Colom, A. J. (1987): op. cit., pp. 221-233.

UNESCO (1979): Enfoque sistémico del proceso educativo, Anaya/Unesco, Madrid.

VARELA, F. J. (1990): Conocer. Las ciencias cognitivas: tendencias y perspectivas. Cartografia de las ideas actuales. Gedisa, Barcelona.

VARIOS (1986): Tecnología y Educación. CEAC, Barcelona.

VARIOS (1993): Teoría de la Educación. Taurus, Madrid.

VÁZQUEZ, G. (1986): "Acción educativa y nuevas tecnologías de la información", en VARIOS: Tecnología y Educación. CEAC, Barcelona, pp. 78-79.

- (1993): "Tecnologías avanzadas y educación", en VARIos: Teoría de la Educación. Taurus, Madrid, pp. 303-321.

VILLANI, P. (1996): La edad contemporánea 1800-1914. Ariel, Barcelona.

WatZlaWicK, P. (1980): El lenguaje del cambio. Herder, Barcelona.

WatZlawick, P., BEAVIN, J. H. y JaCKSON, S. D. (1989): Teoría de la comunicación bumana. Herder, Barcelona ( $7^{\mathrm{a}} \mathrm{ed}$.).

Weber, M. (1964): Economía y sociedad. F.C.E. México, citado por Rodríguez NeIRA, T. (1994).

WIENER, N. (1948): Cybernetics, on control and communication in the animal and the machine. The Technology Press of M.I.T. John Wiley, New York [trad. cast. "Cibernética o el control y comunicación en animales y máquinas" Tusquets, Barcelona, 1985].

- (1950): Cybernetics and Society. The Human Use of Human Beings. Houghton Mifflin Co. Boston [trad. al castellano "Cibernética y Sociedad". Edit. Sudamericana, 1969; trad. al catalán. "Cibernética i societat, Edic. 62, Barcelona, 1965].

- (1995): Inventar. Sobre la gestación y el cultivo de las ideas. Tusquets, Barcelona.

ZYPKIN (1970): Adaptation und Lernen in Kybernetishen Systemen. R. Oldenbourg, Munchen. 